\title{
PRINCIPALES CONCEPTOS Y ÁMBITO DE APLICACIÓN DE LOS REGLAMENTOS GEMELOS ${ }^{*}$
}

\author{
María José Cazorla González
}

Profesora Titular de Derecho civil de la Universidad de Almería

E-mail: mcazorla@ual.es

Mercedes Soto Moya ${ }^{2 *}$

Profesora Titular de Derecho internacional privado de la Universidad de Granada

E-mail: sotomoya@ugr.es

\begin{abstract}
RESUMEN: Este trabajo se centra en los principales conceptos y el ámbito de aplicación del Reglamento gemelos. En particular, se analizan los principales conceptos del Reglamento, como "matrimonio", "unión registrada", "régimen económico matrimonial", "efectos patrimoniales de una unión registrada", "capitulaciones matrimoniales" y " capitulaciones de la unión registrada". A continuación, se analiza el ámbito de aplicación material, personal, temporal y territorial del Reglamento de los Mellizos. Para la correcta interpretación y aplicación de estos instrumentos es esencial comprender claramente en qué casos, a quién y cuándo se aplican los Reglamentos.
\end{abstract}

Palabras clave: concepto de régimen económico matrimonial, capitulaciones de la unión registrada, unión registrada, ámbito material, ámbito temporal, ámbito territorial.

ABSTRACT: This paper focuses on the main concepts and the scope of application of the Twin Regulations. In particular, it analyses the main concepts of the Regulations, such as 'marriage' 'registered partnership', 'matrimonial property regime', 'property consequences of a registered partnership', 'matrimonial property agreement' and 'partnership property agreement. It then discusses the material, personal, temporal and territorial scope of the Twin Regulations. A clear understanding as to in what cases, to whom and when the Regulations apply is essential for the proper interpretation and application of these instruments.

Keywords: concept of matrimonial property regimes, property consequences of registered partnerships, registered partnership, material scope, temporal scope, territorial scope.

\footnotetext{
* Traducido por María José Cazorla González, profesora titular de Derecho civil de la Universidad de Almería. * Autorías: Apartados I, 3.1., 3.3. y 3.4. María José Cazorla González y apartado 3.2. Mercedes Soto Moya. Apartado II. y IV., autoría conjunta.
} 
SUMARIO: I. INTRODUCCIÓN. II. DEFINICIONES Y PRINCIPALES CONCEPTOS. III. AMBITO DE APLICACIÓN DE Los Reglamentos Gemelos. 3.1. Ámbito material de aplicación de los Reglamentos gemelos. 3.1.1. Materias incluidas en el ámbito de aplicación del Reglamento de los gemelos. 3.1.2. Materias excluidas del ámbito de aplicación de los Reglamentos gemelos. 3.2. Ámbito personal de aplicación de los Reglamentos gemelos. 3.3. Ámbito temporal de aplicación de los reglamentos gemelos. 3.3.1. Ámbito temporal de aplicación de las disposiciones de competencia judicial. 3.3.2. Ámbito temporal de las disposiciones sobre reconocimiento y ejecución. 3.3.3. Aplicación temporal de las disposiciones sobre la ley aplicable. 3.4. Ámbito territorial de aplicación de los Reglamentos gemelos. IV. OBSERVACIONES FINALES.

\section{INTRODUCCIÓN}

La Unión Europea se ha fijado el objetivo de mantener y desarrollar un espacio de libertad, seguridad y justicia en el que esté garantizada la libre circulación de personas, de conformidad con el artículo 81, apartado 2, del Tratado de Funcionamiento de la UE (TFUE), garantizando a sus ciudadanos, así como a todas las personas que residan o se encuentren en su territorio, el respeto a la dignidad y derechos que le son inherentes a todos sin distinción . En este ámbito, los Reglamentos gemelos (Reglamento UE 2016/1103 y 2016/1104), que se ubican en un sentido más amplio dentro del marco de la cooperación internacional en materia civil con repercusión transfronteriza, constituyendo un paso importante hacia la unificación del Derecho internacional privado de familia, fundamentándose en los valores de respeto de la dignidad humana, libertad, democracia, igualdad entre hombres y mujeres, atendiendo a lo dispuesto en el art. 2 TFUE.

El camino hacia los Reglamentos gemelos no fue fácil y para su adopción fue necesario recurrir al mecanismo de cooperación reforzada. El mecanismo de cooperación reforzada está regulado en el artículo 20 del Tratado de la Unión Europea (TUE) y en los artículos 326 y siguientes del TFUE; requiere la cooperación de un mínimo de nueve Estados miembros de la $\mathrm{UE}^{3}$.

Este trabajo se centra en los principales conceptos y el ámbito de aplicación del Reglamento gemelos. En particular, se analizan los principales conceptos del Reglamento, como "matrimonio", "unión registrada", "régimen económico matrimonial", "efectos patrimoniales de una unión registrada", "capitulaciones matrimonial" y " capitulaciones de la unión registrada". A continuación, se analiza el ámbito de aplicación material, personal, temporal y territorial del Reglamento de los Mellizos. Para la correcta interpretación y aplicación de estos instrumentos es esencial comprender claramente en qué casos, a quién y cuándo se aplican los Reglamentos.

3 Este procedimiento está diseñado para superar la parálisis, cuando una propuesta es bloqueada por un único país o por un pequeño grupo de países que no desean participar en la iniciativa lo que genera una Europa de "geometría variable". A pesar de esto no se puede obviar el hecho de que las normas aprobadas a través de este mecanismo pueden afectar indirectamente a aquellos Estados UE que no participan de la cooperación reforzada. 


\section{DEFINICIONES Y PRINCIPALES CONCEPTOS}

La armonización y unificación del Derecho de familia en Europa, es muy complicada ${ }^{4}$, debido a que cada país tiene su propia normativa interna respecto a la institución familiar y su reconocimiento, a los efectos patrimoniales que regulan el matrimonio o unión registrada o no, a los procedimientos y causas de extinción o disoluciones de las parejas y respecto a terceros.

Por lo tanto, para poder establecer normas comunes, es necesario unificar algunos términos jurídicos y su uso coherente a nivel europeo. Los Reglamentos gemelos contienen en el artículo 3, la regulación de las principales definiciones de los términos pertinentes. Como es habitual en otras terminologías europeas, todos los términos deben interpretarse de forma autónoma (al margen de las concepciones nacionales) cuando se aplican en la práctica ${ }^{5}$.

Para poder establecer normas comunes, es necesario unificar algunos términos jurídicos y su uso coherente a nivel europeo. Los Reglamentos gemelos contienen el artículo 3 , que determina las principales definiciones de los términos pertinentes. Como es habitual en otras terminologías europeas, todos los términos deben interpretarse de forma autónoma (independientemente de las concepciones nacionales) cuando se aplican en la práctica.

En parte, las definiciones son las mismas en ambos reglamentos (es decir, "decisión", "documento público", "transacción judicial", "Estado miembro de origen" y "Estado miembro de ejecución"). Se trata de términos que tienen el mismo significado en ambos Reglamentos, independientemente de que la pareja haya celebrado una unión registrada o se haya casado ${ }^{6}$, porque las definiciones son las mismas, exceptuando la parte que se refiere a la forma específica de la relación, porque tales términos son comunes para el derecho internacional privado en general y, por lo tanto, también para otros Reglamentos europeos de ese ámbito, si bien, el artículo 3 los define en el ámbito de aplicación del Reglamento de los gemelos.

El resto de los términos del artículo 3 del Reglamento de los gemelos son diferentes y están estrechamente relacionados con las especificidades del contenido de cada reglamento. Así, el Reglamento sobre el régimen económico matrimonial define adicionalmente "régimen económico matrimonial" y "acuerdo económico matrimonial", mientras

4 Vid. N. Dethloff, 'Arguments for the unification and harmonisation of family law in Europe', in K. Boele-Woelki (ed.), Perspectives for the unification and harmonisation of family law in Europe, Intersentia, Belgica 2003, pp. 37-39.

5 B. Reinhartz, 'C. Article 3: Definitions' in U. Bergquist, D. Damascelli, R. Frimston, P. Lagarde and B. ReInhartz, The EU Regulations on Matrimonial and Patrimonial Property, Oxford University Press, Oxford 2019, p. 40.

6 Por ejemplo, en el Reglamento sobre los efectos patrimoniales de las uniones registradas, el término "resolución" se define como "cualquier resolución en materia de efectos patrimoniales de la unión registrada adoptada por un órgano jurisdiccional de un Estado miembro con independencia de la denominación que reciba, incluida una resolución de un funcionario judicial sobre la determinación de las costas o de los gastos"; mientras que en el Reglamento sobre el régimen económico matrimonial se define como “ cualquier resolución en materia de régimen económico matrimonial dictada por un órgano jurisdiccional de un Estado miembro con independencia de la denominación que reciba, incluida una resolución sobre la determinación de las costas o gastos por parte de un funcionario judicial".

7 Para más información sobre el "documento público" y la "transacción judicial", véase el artículo séptimo de este numero de la RIDJ. 
que el Reglamento sobre las consecuencias patrimoniales de las uniones registradas define "unión registrada", "consecuencias patrimoniales de una unión registrada" y "acuerdo patrimonial de la unión".

Curiosamente, ninguno de los Reglamentos gemelos contiene la definición de "familia", que es el fundamento básico y, al mismo tiempo, la razón principal por la que incluso necesitamos instrumentos jurídicos como los Reglamentos 2016/1103 y 2016/1104.

La institución de la familia está en constante evolución dentro y fuera de Europa, lo que hace más difícil definir un modelo de familia única. Por esta razón, ni la UE ni otras organizaciones internacionales están vinculadas a un único concepto de "familia", ni este concepto permanece estático. Más bien, el objetivo es proteger a todas las familias y sus relaciones.

El principio básico de la normativa internacional se encuentra en el artículo 16 de la Declaración Universal de los Derechos Humanos ${ }^{8}$, que se refiere al derecho a contraer matrimonio, a fundar una familia y a la igualdad de derechos de los cónyuges. Dentro de esto, el sistema de las Naciones Unidas (ONU) está abierto a muchas estructuras familiares no tradicionales. Entre ellas, se encuentran las familias monoparentales, las intergeneracionales, las adoptivas, las de padres separados o divorciados y las nucleares, independientemente de que estén formadas por personas del mismo o distinto sexo, incluso en caso de cambio de sexo de uno de los cónyuges. Siguiendo un concepto flexible y dinámico, la UE reconoce el derecho a contraer matrimonio y el derecho a fundar una familia según las leyes nacionales de los Estados miembros de la UE que regulan su ejercicio (artículo 9 de la Carta de los Derechos Fundamentales de la Unión Europea), así como la protección de la familia en los ámbitos jurídico, económico y social (artículo 33.1 de la Carta de los Derechos Fundamentales de la Unión Europea). Asimismo, la Observación General no 19 del Pacto Internacional de Derechos Civiles y Políticos establece que la protección de la familia requiere el reconocimiento de los diferentes tipos de organización o modelos familiares, añadiendo las familias monoparentales y las parejas de hecho en la Observación $23^{9}$.

Estos instrumentos jurídicos han sido aplicados por los tribunales y su interpretación ha ido evolucionando con la aplicación de los principios europeos ${ }^{10}$. Así, el Tribunal Europeo de Derechos Humanos (TEDH) ha reconocido en varias ocasiones un concepto amplio y flexible de familia, centrado en la no discriminación y en el derecho a la igualdad, basado en el respeto a la vida privada y familiar, tal y como establece el artículo 8 del $\mathrm{CEDH}^{11}$.

8 Tribunal Europeo de Derechos Humanos (Gran Sala). Caso Hämäläinen contra Finlandia. Sentencia de 16 julio 2014. TEDH 2014\50. Demanda de ciudadana finlandesa contra la Re-pública de Finlandia, presentada ante el Tribunal el 08-07-2009, por no poder obtener el pleno reconocimiento de su nuevo sexo sin convertir su matrimonio en una unión civil. Violación de los arts. 8, 9 y 14 del Convenio: inexistencia: desestimación de la demanda.

9 S. Sanz Caballero, La familia en perspectiva international y europea, Tirant lo Blach, Valencia 2006, p. 26, and S. SANZ Caballero, 'Familia (en derecho internacional y europeo)' in Diccionario analítico de derechos humanos e integración jurídica $<\underline{\text { http://opendata.dspace.ceu.es/bitstream/10637/7809/1/ }}$ Familia en\%20derecho\%20internacional\%20y\%20europeo.pdf $>$ accessed 30.07.2021.

10 K. Boele-Woelki, 'The principles of European family law: its aims and prospects' (2005) 2 Utrecht Law review 161.

11 European Convention on Human Rights. Rome, 4, November 1950. 
Teniendo en cuenta todo esto, el avance que supone el Reglamento de los gemelos en este delicado ámbito es considerable. Su objetivo es garantizar la seguridad jurídica en las cuestiones causadas por las diversas normas nacionales de Derecho internacional privado relativas a los regímenes patrimoniales de las parejas transfronterizas. Tanto los regímenes matrimoniales como las consecuencias patrimoniales de las uniones registradas forman parte sensu lato del derecho de familia ${ }^{12}$.

Aunque los Reglamentos gemelos no definen el término "familia", si aportan algunos otros conceptos importantes que deben ser analizados.

El Reglamento sobre los efectos patrimoniales de las uniones registradas, en su disposición sobre definiciones, menciona en primer lugar la "unión registrada" (artículo 3 , apartado 1, letra a)). Se define como " régimen de vida en común de dos personas regulado por ley, cuyo registro es obligatorio conforme a dicha ley y que cumple las formalidades jurídicas exigidas por dicha ley para su creación". El propio Reglamento no especifica si esta forma de unión incluye a las parejas del mismo sexo, a las de sexo opuesto o a ambas, dejando esto a las regulaciones nacionales específicas de los diferentes Estados ${ }^{13}$. Sin embargo, sí establece tres elementos de la definición. Estos son (i) la vida en común de dos personas, (ii) la obligación de registrar la pareja, y (iii) el cumplimiento de las formalidades legales exigidas por la ley bajo la que se registra la pareja.

Por lo tanto, la definición exige explícitamente el Registro de la unión. La existencia de la pareja de hecho debe ser certificada por una autoridad pública en un registro público ${ }^{14}$. En consecuencia, la pareja que sólo vive junta, pero no ha registrado una pareja, no cumple las normas, que se establecen en el Reglamento sobre las consecuencias patrimoniales de las parejas de hecho registradas. Por lo tanto, este instrumento jurídico no se aplica a las parejas de hecho, que sólo viven juntas, pero no han registrado su relación (esto se confirma también en el considerando 16). Sin embargo, el registro, necesario para la existencia de una "pareja registrada", no es claramente lo mismo que una institución jurídica como el matrimonio, aunque los efectos de ambos puedan ser en algunos Estados miembros sustancialmente iguales.

La necesidad de una definición del término "unión registrada" radica en los diferentes y diversos enfoques de las parejas registradas en los Estados miembros de la UE. No obstante, la definición de unión registrada sólo puede utilizarse a los efectos del propio Reglamento, mientras que su considerando 17 hace hincapié explícitamente en que el contenido real del concepto debe seguir definiéndose en las legislaciones nacionales de los Estados miembros. Además, no todas las legislaciones nacionales de los Estados miembros de la UE prevén esta forma jurídica de relación. Por ello, el Reglamento so-

12 W. Pintens, 'Union européenne et l'émergence d'un droit international de la famille - L'exemple des régimes matrimoniaux et des effets patrimoniaux des partenariats enregistrés' in C. CALliess (ed), Herausforderungen an Staat und Verfassung; Völkerrecht, Europarecht, Menschenrechte; Liber Amicorum für Torsten Stein zum 70. Geburtstag, Nomos, Baden-Baden 2015, pp. 806-22.

13 Si bien es cierto que esta es una forma de incluir todas las diversas formas nacionales de unión, puede causar cierta incertidumbre a la hora de determinar la competencia judicial o la ley aplicable. Para más información, vid A. Rodriguez Benot, 'Definitions' in I. Viarengo and P. Franzina (eds), The EU Regulations on the Property Regimes of International Couples, A Commentary, Edward Elgar Publishing, Cheltenham 2020, p. 38-39.

14 A. Rodriguez Benot, 'Definitions', op. cit. n. 11, p. 36. 
bre las consecuencias patrimoniales de las uniones registradas subraya explícitamente que nada de lo dispuesto en él debe obligar a un Estado miembro cuya legislación no contemple la institución de la unión registrada a preverla en su legislación nacional (Considerando 17).

Mientras que el Reglamento sobre las consecuencias patrimoniales de las uniones registradas define el término "unión registrada", el Reglamento sobre el régimen económico matrimonial, por el contrario, no establece una definición del término "matrimonio", aunque éste se utiliza varias veces en el Reglamento. El Reglamento sobre los bienes matrimoniales subraya explícitamente que no define este término específico y que el "matrimonio" se define únicamente por las leyes nacionales de los Estados miembros (considerando 17). Aunque este vacío legal puede causar cierta incertidumbre a la hora de aplicar el Reglamento sobre los bienes matrimoniales en la práctica, el término "matrimonio" es ciertamente menos problemático que el de "unión registrada". El matrimonio es una forma antigua y tradicional de relación y, aunque los requisitos para su celebración y posiblemente también sus efectos pueden diferir parcialmente entre los distintos Estados, el término tiene un significado global más seguro y unificado en comparación con el término "pareja registrada". Este último es una forma mucho más reciente de relación formal y varía considerablemente entre las normativas nacionales.

Además, los Reglamentos gemelos definen dos términos que constituyen la base de sus demás disposiciones, "régimen económico matrimonial” y "consecuencias patrimoniales de una unión registrada". Su importancia radica también en que forman parte del título del Reglamento (UE) 2016/1103 del Consejo, de 24 de junio de 2016, por el que se establece una cooperación reforzada en el ámbito de la competencia, la ley aplicable, el reconocimiento y la ejecución de las resoluciones en materia de regímenes económico matrimoniales; y del Reglamento (UE) 2016/1104 del Consejo, de 24 de junio de 2016, por el que se establece una cooperación reforzada en el ámbito de la competencia, la ley aplicable, el reconocimiento y la ejecución de las resoluciones en materia de efectos patrimoniales de las uniones registradas.

Por su parte, el Reglamento 2016/1103 define el "régimen económico matrimonial" como "un conjunto de normas relativas a las relaciones patrimoniales entre los cónyuges y en sus relaciones con terceros, como consecuencia del matrimonio o de su disolución" "15. Se trata de una definición bastante amplia, que no da instrucciones precisas sobre el conjunto de cuestiones patrimoniales que se incluyen en el ámbito de aplicación de este reglamento. Por lo tanto, a la hora de interpretar el término, es necesario tener en cuenta el considerando 18 del Reglamento de régimen económico matrimonial, donde se determina que se incluyen todos los aspectos de derecho civil de los regímenes matrimoniales, que consisten en la gestión diaria de los bienes matrimoniales, por un lado, y la liquidación del régimen, por otro.

El término incluye no sólo los regímenes patrimoniales previstos por algunos ordenamientos jurídicos nacionales en caso de matrimonio, sino también cualquier relación

15 En las legislaciones nacionales de los Estados europeos, el régimen económico matrimonial suele entenderse como un conjunto de normas obligatorias y por defecto que se aplican automáticamente a todas las parejas casadas bajo la ley del Estado o que han elegido la ley del Estado en un contrato matrimonial (prenupcial o post-nupcial). El régimen económico matrimonial que se aplica en un país determinado establece los deberes y derechos mínimos de los cónyuges en cuanto a la gestión y administración de su patrimonio. 
patrimonial, entre los cónyuges y en sus relaciones con terceros derivados directamente de la relación matrimonial, o de la disolución del matrimonio. El respeto de estas instrucciones generales puede verse en el artículo 27 del Reglamento sobre el régimen económico matrimonial, que determina un elenco no exhaustivo de circunstancias que quedan cubiertas con esta definición. Por tanto, la ley aplicable al régimen económico matrimonial en virtud del Reglamento de régimen económico matrimonial regirá:

a) la clasificación de los bienes de uno o ambos cónyuges en diferentes categorías durante la vigencia y después del matrimonio;

b) la transferencia de bienes de una categoría a otra;

c) la responsabilidad de uno de los cónyuges por las obligaciones y deudas del otro cónyuge;

d) las facultades, derechos y obligaciones de cualquiera de los cónyuges o de ambos con respecto al patrimonio;

e) la disolución del régimen económico matrimonial y el reparto, la distribución o la liquidación del patrimonio;

f) los efectos patrimoniales del régimen económico matrimonial sobre la relación jurídica entre uno de los cónyuges y un tercero, y

g) la validez material de las capitulaciones matrimoniales.

A la hora de decidir si una cuestión concreta está incluida en el ámbito de aplicación del Reglamento de régimen económico matrimonial, hay que atender a lo dispuesto en el artículo 1 del Reglamento, porque en el se determina las cuestiones que quedan excluidas de su ámbito de aplicación. Éstas son: las cuestiones fiscales, aduaneras o administrativas, la capacidad jurídica de los cónyuges; la existencia, la validez o el reconocimiento de un matrimonio; las obligaciones alimentarias; la sucesión de los bienes del cónyuge fallecido; la seguridad social; el derecho a la transferencia o al reajuste entre los cónyuges, en caso de divorcio, de separación legal o de anulación del matrimonio, de los derechos a la pensión de jubilación o de invalidez devengados durante el matrimonio y que no hayan generado ingresos de pensión durante el mismo; la naturaleza de los derechos reales relativos a una propiedad; y cualquier inscripción en un registro de derechos sobre bienes inmuebles o muebles, incluidos los requisitos legales para dicha inscripción, y los efectos de la inscripción o la falta de inscripción de dichos derechos en un registro ${ }^{16}$.

En cuanto al término "efectos patrimoniales de una unión registrada" en el Reglamento 2016/1104 en materia de efectos patrimoniales de las uniones registradas. Se define como "conjunto de normas relativas a las relaciones patrimoniales de los miembros de la unión registrada entre sí y con terceros, como resultado de la relación jurídica creada por el registro de la unión o su disolución". Dado que la definición es materialmente la misma que la del régimen económico matrimonial, lo mismo que se ha escrito más arriba sobre su interpretación, es aplicable también aquí (Considerandos 18 y 19) y (Artículos 1 y 27 del Reglamento 2016/1104).

16 Vid. Apartado 3.1.2. 
Siguiendo lo dispuesto en el artículo 27 del Reglamento 2016/1104, la ley aplicable a los efectos patrimoniales de la unión registrada con arreglo al presente Reglamento regulará, entre otras cosas:

- la clasificación de los bienes de uno o ambos miembros de la unión registrada en diferentes categorías durante la vigencia de la unión registrada y después de la misma;

- la transferencia de bienes de una categoría a otra;

- la responsabilidad de uno de los miembros de la unión registrada por las obligaciones y deudas del otro;

- los poderes, derechos y obligaciones de cualquiera de los miembros de la unión registrada o de ambos con respecto al patrimonio;

- el reparto, la distribución o la liquidación del patrimonio en caso de disolución de la unión registrada;

- los efectos patrimoniales de la unión registrada sobre la relación jurídica entre uno de los miembros de la unión registrada y un tercero, y

- la validez material de las capitulaciones de la unión registrada.

Además, los Reglamentos gemelos definen términos similares como "capitulaciones matrimoniales "y "capitulaciones de las uniones registradas". El Reglamento sobre las capitulaciones matrimoniales se interpreta de forma similar las consecuencias patrimoniales de la unión registrada. Estas se definen como "el conjunto de normas relativas a las relaciones patrimoniales de los miembros, entre sí y en sus relaciones con terceros, resultantes de la relación jurídica creada por la inscripción de la pareja de hecho o su disolución" (artículo 3, apartado 1, letra b)). Esto incluye tanto los acuerdos entre los socios, especialmente si la sociedad dura y no se modifica, como los que resultan de su asociación.

Ambos Reglamentos son obligatorios en su totalidad y directamente aplicables solo en los Estados miembros que participan en la cooperación reforzada en el ámbito de la competencia, la ley aplicable, el reconocimiento y la ejecución de resoluciones sobre los regímenes patrimoniales de las parejas internacionales, tanto sobre los regímenes matrimoniales como sobre los efectos patrimoniales de las uniones registradas, en virtud de la Decisión (UE) 2016/954, o en virtud de una decisión adoptada de conformidad con el artículo 331.1, párrafos segundo o tercero, del TFUE (considerando 13).

Dicho convenio (capitulaciones matrimoniales o en uniones registradas) se define como un acuerdo entre los cónyuges/parejas o futuros cónyuges/parejas por el que organizan su régimen económico matrimonial o las consecuencias patrimoniales de su unión registrada, pudiendo concluir que dicho término tiene, por tanto, el mismo significado en ambos reglamentos. Las definiciones se ajustan únicamente a la terminología propia de cada reglamento específico. Mientras que, por un lado, las partes pueden concluir un acuerdo general sobre diferentes aspectos relacionados con la propiedad (es decir, elegir el régimen económico), también pueden acordar la ley aplicable y el 
tribunal competente ${ }^{17}$. De esta forma, ambos Reglamentos proporcionan detalles sobre los requisitos materiales y de procedimiento que deben cumplirse al celebrar dicho acuerdo. Consecuentemente, será más fácil y seguro que los derechos de propiedad adquiridos como resultado de un acuerdo patrimonial sean aceptados en los demás Estados miembros (considerando 48 del Reglamento sobre los bienes matrimoniales).

La definición de los principales términos utilizados en un instrumento de la UE es muy importante desde la perspectiva del proceso legislativo, ya que establece definiciones comunes para todos los reglamentos europeos. Garantiza que los conceptos básicos sean lo más claros posible antes de utilizarlos en una regulación del ámbito jurídico específico. Independientemente de la profundidad y exhaustividad de las definiciones, siempre surgen problemas a la hora de interpretar y utilizar los términos en la práctica. Lo mismo cabe esperar en relación con los términos y definiciones que figuran en el Reglamento sobre los gemelos, y el TJUE desempeñará seguramente un gran papel en su interpretación.

\section{SCOPE OF APPLICATION OF THE TWIN REGULATIONS}

Una vez expuestos los principales conceptos de los Reglamentos, se hace necesario definir el ámbito de aplicación de ambas. En particular, el ámbito de aplicación material, personal, temporal y territorial del Reglamento de Gemelos se expone en las secciones siguientes.

\section{1. Ámbito de aplicación material de los Reglamentos gemelos}

Los Reglamentos gemelos son obligatorios en su totalidad y sólo son directamente aplicables en los Estados miembros que participan en la cooperación reforzada en el ámbito de la competencia, la ley aplicable, el reconocimiento y la ejecución de las resoluciones sobre los regímenes patrimoniales de las parejas internacionales, tanto sobre los regímenes matrimoniales ${ }^{18}$ como sobre los efectos patrimoniales de las uniones registradas. El ámbito de aplicación material de ambos reglamentos incluye todos los aspectos de derecho civil de los regímenes matrimoniales ${ }^{19}$ y los efectos patrimoniales de las uniones registradas. Esto incluye tanto la administración cotidiana de los bienes como la liquidación de los mismos, en particular como consecuencia de la separación judicial, el divorcio, la anulación del matrimonio, el fallecimiento de uno de los cónyuges o de uno de los miembros de la pareja ${ }^{20}$, o la disolución de la unión registrada.

17 B. Reinhartz, 'C. Article 3: Definitions', op. cit. n. 3, p. 41 y 281-82, difiere entre los acuerdos sobre los regímenes económicos matrimoniales/efectos patrimoniales de la unión registrada pareja en general y los acuerdos patrimoniales matrimoniales/de pareja que eligen una ley aplicable. Los antecedentes de ambos tipos de acuerdos se encuentran en los considerandos 46 y 47 del Reglamento sobre los efectos patrimoniales de las uniones registradas y en el considerando 48 del Reglamento sobre el régimen económico matrimonial.

18 U. BERQUIST, D. DAMASCELLI, R. FRIMSTON, P. LAGARDE, B. REINHARTZ: The EU Regulations on matrimonial and patrimonial property, Oxford University Press, Oxford, 2019, pp. 56-57.

19 R. Frimston, op.cit. n. 3, pp. 56-57.

20 Vid. G. Di Benedetto, 'European certificate of succession and rights of the surviving spouse' in J. Kramberger Škerl, L. RugGeri and F. G. Viterbo (eds.), Estudios de casos y análisis de las mejores prácticas para mejorar el derecho de familia y de sucesiones de la UE. Documento de trabajo, Quaderni 
El capítulo I de ambos reglamentos (Ámbito de aplicación y Definiciones) consta de tres artículos que recogen el ámbito de aplicación de los Reglamentos gemelos y los principales conceptos utilizados en él. En los considerandos también se pueden encontrar directrices para su interpretación.

A efectos del Reglamento 2016/1103, el término "régimen económico matrimonial" debe interpretarse de forma autónoma. Como se explica en el considerando 18, este término debe abarcar no sólo las normas que los cónyuges no pueden derogar, sino también cualquier norma opcional que los cónyuges puedan acordar de conformidad con la ley aplicable, así como cualquier norma por defecto de la ley aplicable. Incluye no sólo los regímenes patrimoniales previstos específica y exclusivamente por determinados ordenamientos jurídicos nacionales en caso de matrimonio, sino también todas las relaciones patrimoniales, entre los cónyuges y en sus relaciones con terceros, resultantes directamente de la relación matrimonial, o de su disolución ${ }^{21}$.

El Reglamento 2016/1104, sobre los efectos patrimoniales de las uniones registradas se interpreta de forma similar al reglamento sobre regímenes económicos matrimoniales y se definen como "el conjunto de normas relativas a las relaciones patrimoniales de los miembros, entre sí y en sus relaciones con terceros, resultantes de la relación jurídica creada por la inscripción de la pareja de hecho o su disolución" (artículo 3, apartado 1, letra b)). Esto incluye tanto los acuerdos entre los socios, especialmente si la sociedad dura y permanece inalterada, como los que resultan de su asociación.

Ambos Reglamentos son obligatorios en su totalidad y directamente aplicables únicamente en los Estados miembros que participan en la cooperación reforzada en el ámbito de la competencia, la ley aplicable, el reconocimiento y la ejecución de resoluciones sobre los regímenes patrimoniales de las parejas internacionales, tanto sobre los regímenes matrimoniales como sobre los efectos patrimoniales de las uniones registradas, en virtud de la Decisión (UE) 2016/954, o en virtud de una decisión adoptada de conformidad con el artículo 331.1, párrafos segundo o tercero, del TFUE (considerando 13).

Por otro lado, el ámbito de aplicación temporal, material, territorial y personal del Reglamento vendrá determinado por las disposiciones de las partes o, en su defecto, por la aplicación de las normas de conflicto introducidas por el Reglamento aplicable, considerando los criterios armonizadores que se seguirán para determinar la ley aplicable y

degli Annali della Facoltà giuridica dell'Università di Camerino (2019) 3. En esta publicación el autor analiza el artículo 1 del Reglamento sucesorio of the Succession Regulation, determining that it must be interpreted as meaning that the provisions of a Member State governing matters relating to matrimonial property regimes for the period following the death of one of the spouses fall within its scope. Such conclusion is confirmed by the CJEU case C-558/16, Doris Margret Lisette Mahnkopf $v$. Sven Mahnkopf, ECLI:EU:C:2018:138. It will therefore be possible to insert a right within the European succession certificate, the rationale of which is to compensate for the disadvantaged situation resulting from the interruption of the legal communion regime due to the death of the spouse. Moreover, this interpretation is not contradicted by the scope of application of the Matrimonial Property Regulation, which implements reinforced cooperation in matters of the matrimonial property regime. Although it was adopted to regulate all aspects of civil law regarding matrimonial property regimes (also with reference to the liquidation phase of the marital assets following the death of one of the spouses), the regulation expressly excludes the succession causa mortis of a spouse from its scope of application in Article 1.

21 U. BERQUIST, D. DAMASCELLI, R. FRIMSTON, P. LAGARDE, B. REINHARTZ: The EU Regulations on matrimonial and patrimonial property, Oxford University Press, Oxford, 2019, pp. 56-57. 
el tribunal competente. Teniendo en cuenta, que para garantizar la salvaguarda jurídica de las transacciones, y evitar cualquier cambio en la ley aplicable al régimen económico matrimonial o a los efectos patrimoniales de la unión registrada por elección, las partes deben manifestar expresamente su voluntad. La modificación decidida por los cónyuges o socios no debe tener efectos retroactivos, salvo disposición expresa en contrario. En cualquier caso, no puede perjudicar los derechos de terceros.

\subsubsection{Materias incluídas en el ámbito de aplicación los Reglamentos gemelos}

El artículo 1.1. de los Reglamentos gemelos define de forma positiva el ámbito de aplicación material de forma muy breve. Únicamente establecen que los reglamentos se aplicarán a los regímenes matrimoniales $\mathrm{o}$, respectivamente, a las cuestiones relativas a los efectos patrimoniales de las uniones registradas. Como se ha mencionado anteriormente, el considerando 18 de ambos reglamentos da algunas instrucciones generales sobre las materias que entran en su ámbito de aplicación. Esta definición general del ámbito de aplicación se especifica a continuación mediante la enumeración de las materias excluidas de los reglamentos (véase el apartado 3.1.2).

Es importante subrayar que el Reglamento de los gemelos se aplica a los regímenes matrimoniales y a las cuestiones relativas a las consecuencias patrimoniales de las uniones registradas con implicaciones transfronterizas. Este elemento transfronterizo surge cuando dos o más sistemas nacionales están implicados y pueden considerarse competidores (debido a factores personales, territoriales u objetivos). Por ejemplo, un caso puede referirse a un par de nacionalidades diferentes, que residen en países distintos o que residen en un país distinto al de su nacionalidad ${ }^{22}$. Los casos puramente nacionales entran en el ámbito de la legislación nacional y no se aplica el Reglamento sobre los gemelos. Así lo confirma el considerando 14 de ambos reglamentos, que establece que, de conformidad con el artículo 81 del TFUE, los reglamentos deben aplicarse en el contexto de los regímenes patrimoniales con implicaciones transfronterizas.

\subsubsection{Materias excluidas del ámbito de aplicación de los Reglamentos gemelos}

Aunque los Reglamentos gemelos son breves al señalar las cuestiones que entran en su de su ámbito de aplicación, ofrece una extensa lista de las materias que quedan excluidas de su aplicación.

En primer lugar, el artículo 1(1) en ambos Reglamentos se estipula que no se aplica a las cuestiones fiscales, aduaneras y administrativas de los reglamentos.

En segundo lugar, determina que no se aplica a las cuestiones relativas a la capacidad jurídica general de los cónyuges o parejas (artículo 2(a)), al considerar que se trata de una cuestión que debe ser regulada por la legislación nacional de cada Estado Sin embargo, esta exclusión es limitada, y, por lo tanto, no debe abarcar las facultades y derechos específicos de uno de los cónyuges o de ambos con respecto a los bienes, ya sea entre ellos o con respecto a terceros, ya que estas facultades y derechos deben entrar en el ámbito de aplicación del presente Reglamento (considerando 20 de ambos reglamentos).

22 Vid. A. Rodriguez Benot, 'Article 1. Scope' in I. Viarengo and P. Franzina (eds.), The EU Regulations on the Property Regimes of International Couples, A Commentary, Edward Elgar, Cheltenham 2020, p. 132. 
La exclusión también se aplica a las cuestiones preliminares, como la existencia, la validez o el reconocimiento de un matrimonio o de una unión registrada (letra b) del artículo 2). De manera que estas cuestiones siguen rigiéndose por el Derecho nacional de los Estados miembros, incluyendo sus normas de Derecho internacional privado (considerando 21 de los Reglamentos gemelos).

Respecto a las obligaciones alimentarias también están excluidas de los Reglamentos gemelos, siguiendo lo dispuesto en la letra c) del artículo 2), ya que existen instrumentos separados que tratan de este ámbito. En particular, el Reglamento sobre alimentos y el Protocolo de La Haya sobre de 2007 se aplican a este respecto. Por la misma razón, los Reglamentos gemelos no se aplican a la sucesión del cónyuge fallecido, pues el Reglamento sobre Sucesiones regula este ámbito (véase el asunto Mahnkopf (C-558/16) a este respecto $)^{23}$.

Otro ámbito de exclusión de la aplicación de los Reglamentos gemelos es el referido a la seguridad social, letra e) del artículo 2), que queda en manos del derecho nacional de los Estados miembros. Así como cuestiones de derechos sobre la transferencia o adaptación entre cónyuges de los derechos a la jubilación o a la pensión de invalidez, cualquiera que sea su naturaleza, devengados durante el matrimonio y que no han generado ingresos por pensiones durante el matrimonio. Estas son cuestiones que también están excluidas del ámbito de aplicación de ambos reglamentos (artículo 2 letra f). Sin embargo, como se explica en el considerando 23, esta exclusión debe interpretarse de manera estricta y los Reglamentos gemelos deben regular, en particular, la cuestión de la clasificación de los activos de las pensiones, los importes que ya se han pagado a uno de los cónyuges durante el matrimonio, y la posible compensación que se concedería en caso de una pensión abonada con bienes comunes.

También se excluye del ámbito de aplicación de los Reglamentos gemelos la naturaleza de los derechos reales relativos a un bien $^{24}$, (letra g) del artículo 2), al igual que cualquier inscripción en un registro de derechos sobre bienes muebles o inmuebles, incluidos los requisitos legales para dicha inscripción, así como los efectos de la inscripción o de la falta de la misma (artículo 2, letra h)). Pues corresponde a la legislación del Estado miembro determinar si la inscripción es, por ejemplo, declarativa o constitutiva, declaratoria o constitutiva.

De esta lista, cabe recordar que, en virtud de la unidad de la ley aplicable al régimen económico matrimonial o a los efectos patrimoniales de las uniones registradas, los artículos 22 o 26 se aplicarán a todos los bienes incluidos en dicho régimen, con indepen-

23 Vid. A. Pérez Vallejo, 'Notas sobre la aplicación del Reglamento (UE) 2016/1103 a los pactos prematrimoniales en previsión de la ruptura matrimonial' (2019) 21 Revista Internacional de Doctrina y Jurisprudencia, p. 112.

24 SENTENCIA DEL TRIBUNAL DE JUSTICIA (Sala Segunda), de 12 de octubre de 2017. C-218/16, ECLI:EU:C:2017:755. En el presente asunto, tanto el legado "by vindication", previsto por el Derecho polaco, como el legado 'by damnation' u obligacional, previsto por el Derecho alemán, constituyen modalidades de transmisión de la propiedad de un bien. Así, cuando la transmisión directa de un derecho de propiedad mediante un legado "by vindication" sólo afecte a las modalidades de transmisión de ese derecho real al fallecer el testador, tal transmisión bajo el considerando 15 del Reglamento n. 650/2012 permite de conformidad con la ley aplicable a la sucesión, a tenor del artículo 31 del citado Reglamento referido a la adaptación de los derechos reales: "Cuando una persona invoque un derecho real que le corresponda en virtud de la ley aplicable a la sucesión y el Derecho del Estado miembro en el que lo invoque no reconozca ese derecho real en cuestión, este deberá, en caso necesario y en la medida de lo posible, ser adaptado al derecho real equivalente más cercano del Derecho de ese Estado, teniendo en cuenta los objetivos y los intereses que aquel derecho real persiga y los efectos inherentes al mismo". 
dencia del lugar en que se encuentren, lo que incrementa significativamente su posible ámbito de aplicación, ya que ambos Reglamentos permiten la creación o la transmisión de un derecho sobre bienes muebles o inmuebles resultantes del régimen económico matrimonial o de las relaciones patrimoniales de los inscritos de la pareja registrada, tal y como establece la ley aplicable a los efectos patrimoniales de los matrimonios o de las uniones registradas. Sin embargo, no debe afectar al número limitado ("numerus clausus") de los derechos reales reconocidos en algunos Estados miembros, como se ha visto en el caso Kubicka, en el que la adaptación al derecho real equivalente más cercano en la legislación de ese Estado, atendiendo a los objetivos e intereses perseguidos por ese derecho real y los efectos inherentes al mismo entraban en conexión con el Reglamento sucesorio y, en consecuencia, bajo su aplicación. Sin embargo, esto no implica que un Estado miembro esté obligado a reconocer como derecho real a los bienes situados en ese Estado miembro si tal derecho real en cuestión no está reconocido en su legislación ${ }^{25}$.

\section{2. Ámbito de aplicación personal de los Reglamentos gemelos}

Al igual que otros instrumentos de Derecho internacional privado de la familia de la UE, los Reglamentos gemelos se aplican independientemente de la nacionalidad, la residencia habitual o el domicilio de los cónyuges (en el caso del Reglamento sobre los bienes matrimoniales) o de las parejas (en el caso del Reglamento sobre las consecuencias patrimoniales de las uniones registradas).

Los Reglamentos gemelos se aplican incluso si los cónyuges o las parejas son ciudadanos de fuera de la UE o residen fuera de la UE. Cuando el caso tiene efectos transfronterizos y se inicia en el Estado miembro que participa de la cooperación reforzada, las disposiciones de ambos reglamentos se activan y deben tenerse en cuenta. Dicho de otro modo, el tribunal que conoce de un asunto tiene que comprobar simplemente si se cumplen los criterios de competencia y de ley aplicable establecidos en los Reglamentos, sin que se requiera o aplique ningún otro criterio de conexión.

Un caso reciente ante el Tribunal de Apelación de Arnhem-Leeuwarden (Gerechtshof Arnhem-Leeuwarden) trataba de la división de los bienes comunes de dos ex cónyuges. En su demanda, la ex-esposa (que vive en los Países Bajos) solicitó al tribunal la división de los bienes situados en los Países Bajos que no fueron divididos durante el divorcio. Se estableció que el exmarido tiene nacionalidad nigeriana, no reside en los Países Bajos y (probablemente) vive en Nigeria (por lo tanto, el caso tenía aspectos transfronterizos).

El tribunal observó que el Reglamento 2016/1103, sobre los regímenes económicos matrimoniales tiene un ámbito de aplicación formal (no escrito) universal con respecto al régimen de jurisdicción. Por lo tanto, no importa para la aplicabilidad del Reglamento que el Estado en cuestión (Nigeria) no sea un Estado miembro de la UE. Por lo tanto, el Tribunal de Apelación evaluó la competencia del tribunal neerlandés basándose en el Reglamento sobre el régimen económico matrimonial ${ }^{26}$.

25 I. VIARENGO and P. FRANZINA, The EU regulations on the property regimes of international couples. A Commentary, Edward Elgar, Cheltenham 2020, p. 22.

26 Tribunal de Apelación Arnhem-Leeuwarden (Gerechtshof Arnhem-Leeuwarden), decision of 16 March 2021, No. 200.277.891 / 01 (ECLI: NL: GHARL: 2021: 2490). 
Además, cabe mencionar que no es relevante dónde se encuentran los bienes de la pareja. Incluso si los bienes de la pareja están situados en un tercer país (ya sea un país de la UE que no participa de ambos Reglamentos un país de fuera de la UE), un tribunal de un Estado miembro participante que conozca del caso debe aplicar el Reglamento. Esta norma se aplica tanto a las disposiciones jurisdiccionales como a las disposiciones sobre la ley aplicable. Como señala Franzina ${ }^{27}$, el artículo 13 sobre las limitaciones de los procedimientos y el artículo 21 sobre la unidad de la ley aplicable, entre otros, reflejan precisamente esa interpretación.

Si imaginamos ambos Reglamentos gemelos como círculos secantes, tanto las parejas de hecho como las registradas del mismo sexo estarían en la zona de convergencia entre ambos. La razón fundamental es que, al igual que el matrimonio entre personas del sexo opuesto es una institución consolidada que ha permanecido intacta e incuestionable a lo largo del tiempo, las parejas del mismo sexo podrían calificarse de "institución líquida" (acuñando la categoría central sobre la que el autor construyó su edificio conceptual) ${ }^{28}$. Las antiguas instituciones (solidas) están siendo sustituidas por otras más flexibles.

En el ámbito de las parejas del mismo sexo, cada país o incluso región (por ejemplo, en el caso de España) las regula de forma diferente. Por ejemplo, algunos países no permiten que las parejas del mismo sexo se registren, sino sólo que se casen (por ejemplo, Finlandia y Sudán $)^{29}$. Y desde el 1 de octubre de 2017, las parejas del mismo sexo en Alemania ya no pueden celebrar una unión civil registrada ${ }^{30}$, sino que pueden casarse, aunque las uniones civiles previamente registradas siguen existiendo y pueden ser convertidas en matrimonio por el registro civil previa solicitud. ¿Se aplica en estos países el Reglamento sobre las consecuencias patrimoniales de las uniones registradas a las parejas del mismo sexo registradas en otro Estado? En otras palabras, ¿consideran que la pareja del mismo sexo registrada es una institución no reconocida y la asimilan al matrimonio o, por el contrario, consideran que el Reglamento sobre las consecuencias patrimoniales de la unión registrada sí se les aplica? ${ }^{31}$.

27 P. Franzina, 'Chapter I. Scope and Definitions', op.cit. n. 11, p. 14-16.

28 Z. BAUMAN, Liquid Modernity, Cambridge, Polity Press, 2000.

29 La Ley de matrimonio del mismo sexo sueca que entró en vigor a finales de abril de 2009, derogó la Ley de uniones registradas que continúa, no obstante, produciendo efectos jurídicos respecto de las parejas que registraron su unión antes de finales de abril de 2009 y no han convertido su unión en matrimonio desde entonces. En Finlandia, el matrimonio del mismo sexo es legal desde marzo de 2017, de acuerdo con la ley aprobada por el parlamento el 12 de diciembre de 2014, por lo que también se ha derogado la ley de parejas registradas (Lagom ändring av äktenskapslagen, 156/2015. Disponible en http://www.finlex.fi/sv/laki/alkup/2015/20150156).

30 Gesetz zur Einführung des Rechts auf Eheschließung für Personen gleichen Geschlechts (EheRÄndG k.a.Abk.), G. v. 20.07.2017 BGB1. I S. 2787 (Nr. 52); Geltung ab 01.10.2017. https://www.buzer.de/gesetz/12739/index.htm Amends the Civil Code in Articles 1309.3 and 1353.1.

31 R. GARETTO, 'Uniones registradas y efectos patrimoniales (Registered partnerships and property consequences) in L. RUGGERI, M. GIOBBI, M.J. CAZORLA GONZALEZ, J. KRAMBERGER ŠKERL, S. WINKLER (eds), Property relations of cross-border couples in the European Union, in Edizioni Scientifiche Italiane, p. 91. En el pasado, antes de que se concediera a las parejas del mismo sexo el derecho a contraer matrimonio, en otros cinco Estados Miembros (Alemania, Dinamarca, Finlandia, Irlanda y Suecia) se les permitía registrar su pareja y esas parejas registradas siguen siendo válidas en esos Estados Miembros si las partes no han optado por convertirlas en matrimonio. Por otra parte, nueve Estados Miembros también permiten que las parejas del sexo opuesto, además de las parejas del mismo sexo, registren su unión (Austria, Bélgica, Chipre, Estonia, Francia, Grecia, Luxemburgo, Malta, Países Bajos), y dos Estados miembros (Portugal y España), no han previsto el 
Por el contrario, en algunos otros Estados (Croacia, Eslovenia, Hungría, Italia y la República Checa) las parejas del mismo sexo no tienen acceso al matrimonio, sino que sólo pueden formar una pareja registrada. Lo mismo ocurre en Italia o Austria, con algunas diferencias respecto a Italia, por ejemplo ${ }^{32}$. En estos países, en lugar de crear una institución completamente nueva, simplemente se decidió qué derechos no tienen las parejas registradas que sí tienen las casadas. Sólo pueden registrarse las parejas del mismo sexo, ya que las parejas de distinto sexo pueden optar por casarse o simplemente cohabitar. El registro de la pareja de hecho produce efectos equivalentes al matrimonio en casi todos los ámbitos ${ }^{33}$. En estos casos, ¿se aplica a las parejas registradas en estos Estados el Reglamento sobre las consecuencias patrimoniales de la unión registrada o el Reglamento sobre el patrimonio matrimonial, donde se asimilan al matrimonio ${ }^{34}$.

La elección de una u otra normativa no es una cuestión baladí, dadas las notables diferencias entre ambas en cuanto a la ley aplicable y su posible conexión con la nacionalidad y la residencia habitual. Como se ha visto, la utilización del factor de conexión de la residencia habitual no siempre garantiza la aplicación de una ley que, aunque esté estrechamente vinculada a la pareja, se conoce con la institución de la unión registrada. Por ello, el Reglamento sobre las consecuencias patrimoniales de las uniones registradas permite la aplicación de la ley del Estado bajo cuya ley se creó la unión registrada. Esto garantiza el reconocimiento de la constitución de una unión registrada y, por lo tanto, ofrece a las partes una mayor seguridad jurídica.

Si se acepta que las normas de la UE puedan aplicarse o no a una misma unión por la orientación sexual de sus miembros, en función del Estado miembro en el que se encuentre, se rompe la uniformidad pretendida. Desde el punto de vista del Derecho internacional privado, debe buscarse la continuidad de las relaciones jurídicas.

Además, es necesario evitar la alteración del estatuto personal del ciudadano dentro del propio espacio comunitario, ya que ello va en detrimento del enfoque unitario de las soluciones deseables ${ }^{35}$. Indudablemente, la solución sería la creación de conceptos autónomos con los que se podría lograr una unificación del derecho de familia. Sin embargo, la UE no tiene actualmente la competencia para hacerlo ${ }^{36}$. Se ha considerado que

registro de parejas de hecho, pero permiten que las parejas del mismo sexo se casen o se unan si bien en España algunas de sus Comunidades Autónomas lo han regulado). Por último, en seis Estados Miembros (Bulgaria, Eslovaquia, Letonia, Lituania, Polonia y Rumania) no se prevé ninguna forma de unión registrada ni se permite el matrimonio entre personas del mismo sexo.

32 Italian Law 76/2016 on civil unions, (GU n.118 of 21-05-2016) and Eingetrangene Partnershaft-Gesetz (EPG), 30 December 2009, in Austria.

33 F. SWEDDEN, and S. EGGERMONT, 'Same-sex Couples in Central Europe: Hop, Step and Jump', Legal Recognition of Same-Sex Relationships in Europe. National, Cross-border and European Perspectives. Intersentia, Cambridge 2012, pp. 19-40.

34 D. MARTINY, 'Die Kommissionsvorschläge für das internationale Ehegüterrrecht Bowie für das internationale Güterrrecht eingetrangener Partnerschaften', IPRax, 2011, pp. 443 and following; S. MARINO, 'Strengthening European Civil Judicial Cooperation: The Property Effects of Family Relationships', Cuadernos de Derecho Transnacional, 1, 2017, pp. 265-284.

35 E. ARTUCH IRIBERRI, "La libertad individual y las parejas ante el Derecho internacional privado”,Revista española de Derecho internacional, LIV, 2002, pp. 41-65.

36 Sobre la unificación del Derecho de familia comunitario y la competencia o incompetencia de la UE para abordar esta labor vid. M. ANTOKOLSKAIA, 'Would the Harmonisation of Family Law Enlarge the Gap between the Law in the Books and the Law in Action?', FamPra., 2002, pp. 261- 
el derecho de familia pertenece al núcleo duro de las materias civiles que se resisten a la unificación. Se considera que tal solución supondría la desaparición del derecho privado nacional y la creación de un nuevo derecho europeo aplicable indistintamente a las situaciones internas e intracomunitarias. Por tanto, la creación de conceptos autónomos es actualmente inviable, y la ausencia de un derecho de familia sustantivo en la UE provoca una gran inestabilidad en el estatuto de las parejas móviles.

Sin embargo, en esta materia, el TJUE ha abierto una interesante vía a través de las complejidades de la competencia exclusiva de los Estados con el famoso caso Coman, que se refería a la libre circulación de una pareja casada del mismo sexo dentro de la UE, cuyas principales tesis pueden, en nuestra opinión, extrapolarse a las parejas registradas ${ }^{37}$. El TJUE ha sostenido que el estado civil de las personas, que incluye las normas sobre el matrimonio, es una cuestión que es competencia exclusiva de los Estados miembros. Los Estados miembros son libres de permitir o rechazar los matrimonios entre personas del mismo sexo en su legislación. Sin embargo, en el ejercicio de esta competencia, no pueden infringir la libertad de circulación de los ciudadanos de la UE. En otras palabras, el TJUE exige el reconocimiento de este tipo de matrimonio únicamente a efectos de conceder un derecho de residencia derivado a un nacional de un tercer país, afirmando que ello no atenta contra la identidad nacional ni amenaza el orden público del Estado miembro en cuestión ${ }^{38}$.

El argumento del TJUE puede llevarnos a afirmar que una institución válidamente constituida en un Estado miembro debe ser reconocida en otro Estado miembro, aunque sea con el único fin de garantizar la libre circulación de personas. En el caso del Reglamento sobre las consecuencias patrimoniales de las uniones registradas, se plantea la cuestión de su aplicación a las parejas registradas del mismo sexo ${ }^{39}$. Y aunque esto no su-

292; J. BASEDOW, 'Codification of Private Law in the European Union: the Making of a Hybrid', ERPL, 2001, pp. 35-49; G.R. DE GROOT, 'Auf dem Wege su einem europäischen (internationales) Familienrecht '", ZEuP, 2001, pp. 617-627.

37 Vid. M. SOTO MOYA, 'Libre circulación por el territorio de la Unión Europea de los matrimonios del mismo sexo celebrados en España', Revista de Derecho Comunitario Europeo, no. 43, Madrid, September/December 2012, pp. 807-847; W. PINTENS, 'Europeanisation of Family Law', Perspectives for the Unification and Harmonisation of Family Law in Europe, Intersentia, Belgium 2003, p. 6.

38 For an analysis of this judgement see, among others, S. ÁLVAREZ GONZÁLEZ, 'Same-sex marriage for the whole EU? Regarding the conclusions of the General Counsel in the Coman Affair', The European Union Law 56, 2018; M. REQUENA CASANOVA, 'Free movement of same-sex marriages celebrated in the territory of the European Union: consequences of the Coman and others matter', Journal of European Community Law , 23, No. 62, 2019; P. JIMÉNEZ BLANCO, 'Cross-border mobility of same-sex marriages: the EU takes a step: Judgment of the CJEU of June 5, 2018, case C- 673/18: “Coman', The European Union Law, 61, 2018; and STOPPIONI, 'Une analyze critique de l'arrêt Coman: déconstruction de la consécration de l'obligation de reconnaissance du droit de séjour du conjoint homosexuel', European Papers, European Forum, February 27, 2019, pp. 1 and et seq.; V. STEHLÍK, 'The CJEU crossing the Rubicon on the same-sex marriages? Commentary on the Coman case', International and Comparative Law Review, 18, No. 2, 2018, pp. 85-99; D. KOCHENOV, and U. BELAVUSAU, 'Same-Sex Spouses: More Free Movement, but What About Marriage?', Coman: Case C-673/16, Coman et al. v. Inspectoratul General Pentru Imigrări, Judgement of the CJEU of 5 June 2018, Common Market Law Review, 57 (1), 2020, pp. 227-242.

39 STJUE 5 junio 2018, C-673/16, Coman-Hamilton. Aborda el caso de un ciudadano rumano (Coman) que contrajo matrimonio en Bruselas con un nacional norteamericano (Hamilton). El Sr. Hamilton deseaba trasladarse a vivir a Rumanía con su cónyuge, el Sr. Coman, al amparo de la Directiva 2004/38/ CE de 29 abril 2004 relativa al derecho de los ciudadanos de la Unión y de los miembros de sus familias 
pone una unificación de conceptos ni una injerencia en los derechos de familia nacionales de cada Estado, sí abre la puerta a la obligación de reconocer la institución existente. Por esta vía indirecta se puede generar una cierta homogeneización de conceptos en la UE.

Se puede decir que el Reglamento sobre las consecuencias patrimoniales de la unión registrada es un hito en la construcción del Derecho internacional privado de la UE, ya que nunca antes se había redactado una norma de estas características con las uniones registradas como protagonistas. La diversidad de instituciones con las que cada Estado regula las parejas de hecho ha trasladado el Derecho internacional privado a un terreno mucho más complejo y variado que en el pasado. Ya no se puede hablar ni de universalidad de las instituciones ni de uniformidad de su contenido, a diferencia de lo que ha ocurrido tradicionalmente con la institución del matrimonio entre personas del mismo sexo. Precisamente porque la regulación del régimen patrimonial de las parejas registradas en la UE es tan novedosa, es obvio que su aplicación es compleja.

Una de las cuestiones interpretativas más trascendentales y complicadas se refiere al ámbito de aplicación personal. Antes de especificar qué autoridad es competente, o qué ley se aplica para determinar el régimen patrimonial de la pareja, la autoridad judicial tiene que establecer si el Reglamento sobre las consecuencias patrimoniales de las uniones registradas se aplica en un caso concreto.

El Reglamento sobre las consecuencias patrimoniales de la unión registrada define las uniones registradas como "el régimen de vida en común de dos personas previsto por la ley, cuyo registro es obligatorio en virtud de ésta y que cumple las formalidades legales exigidas por dicha ley para su creación" (artículo 3, apartado 1, letra a)). Además, su considerando 16 limita la aplicación del reglamento a "las parejas cuya unión esté sancionada institucionalmente por el registro de su pareja ante una autoridad pública". Por lo tanto, parece claro que cualquier pareja que no esté registrada no entra en el ámbito de aplicación personal de este reglamento de la UE, descartando por completo a las parejas de hecho, o quizás más exactamente, a las parejas no registradas ${ }^{40}$. La razón, según el propio reglamento, es que su carácter oficial permite considerar su especificidad y proceder a su regulación en el derecho de la UE. Algunos autores interpretan la definición del artículo 3.1.a) de forma aún más flexible, entendiendo que "lo importante es que se trate de una pareja regulada con un régimen patrimonial o de bienes más o menos unitario, y que esté registrada o se haya formalizado, de cara a la sociedad, ante la autoridad pública"41.

a circular y residir libremente en el territorio de los Estados miembros. Las autoridades rumanas denegaron la petición de residencia del Sr. Hamilton en Rumanía porque el Código Civil de dicho país prohíbe los matrimonios entre personas del mismo sexo y no reconoce tales matrimonios en Rumanía aunque se hayan celebrado válidamente en otros países.

40 Hay autores que consideran que de acuerdo con una interpretación finalista las uniones que quedan bajo el amparo del Reglamento no son tanto las que se inscriben en un registro como aquellas en las que los miembros han hecho una declaración de voluntad expresa de querer constituir una unión, se haya inscrito o no dicha declaración de voluntad, Garrido Melero, M., "Las uniones registradas en el ámbito del Reglamento europeo 1104/2016, del Consejo de 24 de junio", Los reglamentos UE 2016/1103 y 2016/1104 de regímenes económicos matrimoniales y efectos patrimoniales de las uniones registradas, Marcial Pons, 2020, pp.48-72, p.55.

41 A. QUIÑNONES ESCÁMEZ, 'Problemas generales de derecho internacional privado en los nuevos reglamentos europeos en materia de regímenes matrimoniales y efectos patrimoniales de las unions, International law and international relations courses in Vitoria-Gasteiz, 1, 2018, pp. 245-335, p. 281. 
Sin embargo, esta afirmación no aclara muchas otras cuestiones que se plantean, como el país de registro, la naturaleza del mismo o si las parejas del mismo sexo registradas están incluidas o no en su ámbito de aplicación.

Como se ha indicado anteriormente, la condición sine qua non que establece el artículo 3 (1)(a) para que se aplique el Reglamento sobre las consecuencias patrimoniales de las parejas de hecho registradas es el registro de la pareja. Lo que no está claro es si la pareja tiene que registrar la pareja en uno de los Estados vinculados por el reglamento (recordemos que se trata de una norma de cooperación reforzada de la que no forman parte todos los países de la UE), o puede hacerlo en otros Estados miembros de la UE, o incluso en cualquier otro Estado del mundo.

La falta de concreción del reglamento no orienta a ninguna de las opciones. A primera vista, parece que su aplicación se limita a las parejas registradas en un Estado vinculado al Reglamento sobre las consecuencias patrimoniales de las uniones registradas. Sin embargo, esta solución parece muy restrictiva y no se ajusta al espíritu y la finalidad del Reglamento de la UE. En primer lugar, el apartado 1 del artículo 3 del Reglamento sobre las consecuencias patrimoniales de las uniones registradas establece que "la unión registrada es un régimen de convivencia de dos personas regulado por la ley, cuyo registro es obligatorio en virtud de dicha ley", pero no añade que tenga que ser la ley de un Estado miembro. El segundo argumento a favor de la ampliación es que el Reglamento de régimen económico matrimonial paralelo no limita su aplicación a los matrimonios celebrados en un Estado miembro vinculado a él, sino a los celebrados en cualquier país del mundo. Ambos reglamentos se elaboraron al mismo tiempo y entraron en vigor el mismo día ${ }^{42}$. El contenido de ambos instrumentos jurídicos está estructurado de forma idéntica, abordando la competencia, la ley aplicable, el reconocimiento de decisiones y documentos, la fuerza ejecutiva frente a terceros, y concluyendo con disposiciones generales y finales. De hecho, en un principio se pretendía incluir ambas materias en un único reglamento, pero esto resultó imposible y se dividieron ${ }^{43}$. Teniendo en cuenta todas estas circunstancias, no parece descabellado pensar que, al igual que el Reglamento de Bienes

42 Los Reglamentos entraron en vigor el 28 de julio de 2016, a los veinte días de su publicación en el Diario Oficial de la Unión Europea (art. 70 de ambos Reglamentos).

43 El germen de estos dos instrumentos jurídicos se encuentra en el "Plan de Acción del Consejo y la Comisión sobre la mejor manera de aplicar las disposiciones del Tratado de Ámsterdam relativas a la creación de un espacio de libertad, seguridad y justicia" (DOCE C 19, de 25 de enero de 1999). Si bien en aquel momento nada se indicaba sobre las uniones more uxorio, muy poco después se incorporó a la agenda, a raiz del "Proyecto de medidas para la aplicación del principio de reconocimiento mutuo de las resoluciones judiciales en materia civil y mercantil”" (DO C 12 de 15.1.2001), que preveía la elaboración de un instrumento sobre la "competencia judicial, el reconocimiento y la ejecución de las resoluciones en materia de los regímenes matrimoniales y las consecuencias patrimoniales de la separación de parejas no casadas". El Programa de Estocolmo, adoptado por el Consejo Europeo el 11 de diciembre de 2009, declaró que el reconocimiento mutuo debe extenderse a los regímenes matrimoniales y a las consecuencias patrimoniales de la separación de la pareja. Y, en el "Informe 2010 sobre la ciudadanía de la Unión: la eliminación de los obstáculos a los derechos de los ciudadanos de la UE" (COM (2010) 603), adoptado el 27 de octubre de 2010, la Comisión señaló que la incertidumbre respecto de los derechos de propiedad de las parejas internacionales era uno de los principales obstáculos a los que se seguían enfrentando los ciudadanos de la UE en su vida cotidiana cuando ejercitan los derechos que les reconoce la UE más allá de las fronteras nacionales. Finalmente se optó por desdoblar la regulación para los matrimonios y las parejas registradas. 
Matrimoniales se aplica a los matrimonios celebrados en cualquier país del mundo, también el Reglamento sobre las Consecuencias Patrimoniales de las Parejas de Hecho se aplique a las parejas de hecho registradas con independencia del estado de la inscripción.

En tercer lugar, es necesario recordar el carácter universal de la ley aplicable designada por las normas del Reglamento sobre las consecuencias patrimoniales de las uniones registradas (artículo 20). Sería incoherente que la autoridad competente del Estado en cuestión pudiera aplicar la ley de cualquier país del mundo para resolver un problema relacionado con el régimen patrimonial de una pareja, pero que al mismo tiempo restringiera la aplicación del reglamento únicamente a las parejas registradas en un Estado miembro.

Por último, cabe destacar que hay otras normas de la UE que han limitado específicamente su aplicación a las parejas registradas en un Estado miembro ${ }^{44}$. Por ejemplo, la Directiva 2004/38 del Parlamento Europeo y del Consejo relativa al derecho de los ciudadanos de la Unión y de los miembros de sus familias a circular y residir libremente en el territorio de los Estados miembros. Su artículo 2, apartado 2, letra b), permite la libre circulación de las personas con un carácter derivado específicamente de "la pareja con la que el ciudadano de la Unión haya establecido una unión registrada, de conformidad con la legislación de un Estado miembro", frase que no se ha incluido en el Reglamento sobre las consecuencias patrimoniales de las uniones registradas ${ }^{45}$.

La inclusión o no de las uniones registradas del mismo sexo en el ámbito de aplicación del Reglamento sobre las consecuencias patrimoniales de las uniones registradas ha sido la principal manzana de la discordia en las negociaciones, y una de las principales razones por las que no todos los Estados miembros de la UE han aceptado formar parte de él. De nada han servido todos los esfuerzos por disipar cualquier duda sobre la total libertad de los países para regular "el contenido real del concepto de unión registrada" (considerando 17). Incluso se renuncia a crear un contenido homogéneo, que sería imprescindible para dotar a la norma de un mínimo de seguridad jurídica ${ }^{46}$.

Este modus operandi no debe sorprender, ya que el legislador de la UE no suele elaborar conceptos autónomos en el ámbito del Derecho de familia, sino que en la mayoría de los casos transfiere esta tarea a los ordenamientos jurídicos de los Estados miembros. Esta remisión -también presente en el Reglamento Bruselas II bis, en el Reglamento sobre alimentos, en el Reglamento Roma III y en el Reglamento sobre bienes matrimoniales- es la razón por la que cada Estado interpreta los conceptos introducidos en el Derecho de la UE según sus propios criterios. Así, existe una inevitable heterogeneidad en el ámbito de aplicación material del Derecho de la $\mathrm{UE}^{47}$.

44 OJ L 158, 30 abril 2004. corrección de errores, OJ L 229/35, 29.06.2004.

45 Vid. M. SOTO MOYA, 'El Reglamento 1104/2016 sobre régimen patrimonial de las parejas registradas: algunas cuestiones controvertidas de su puesta en funcionamiento en el sistema español de DIPr.', REEI, no. 35, December 2018.

46 En palabras de A. RODRÍGUEZ BENOT, 'The concept of a registered partner in Regulation 1104/2016 is merely functional as it can only be used for the purposes of that EU standard', in I. VIARENGO, P. FRANZIN (coord) Article 1: Scope, The EU regulations on the property regimes of international couples: A commentary, Edward Elgar, 2020, pp.17-28.

47 Un extenso análisis de la aplicación de estos Reglamentos UE a las uniones del mismo sexo puede verse en M. SOTO MOYA, Uniones transfronterizas entre personas del mismo sexo (Cross-border unions between people of the same sex), Tirant Lo Blanch, Valencia 2013. 
La neutralidad del Reglamento de la UE con respecto a la inclusión de las parejas del mismo sexo hace que en todos los casos relativos a su régimen económico sea imprescindible resolver en primer lugar la cuestión de si están o no incluidas en su ámbito de aplicación. Dicha cuestión puede resolverse de forma diferente según el Estado miembro de la UE en el que se produzca la disolución de la pareja, el Estado miembro de la UE que se ocupe de la sucesión de uno de los miembros de dicha pareja, el Estado miembro de la UE en el que deseen realizar un acuerdo ...., etc.

Por ejemplo, el Sr. A, de nacionalidad belga, y el Sr. B, de nacionalidad francesa, contraen matrimonio en Bélgica en enero de 2020. Poco después trasladan su residencia habitual a Italia. En julio de 2021 pretenden divorciarse y liquidar su régimen económico matrimonial. ¿Serán competentes las autoridades italianas? La cuestión preliminar antes de determinar si se aplican los Reglamentos 2201/2003 y 1103/2016, respectivamente, es si las autoridades italianas consideran que el Sr. A y el Sr. B son cónyuges o no. En principio, cada Estado es soberano para decidir sobre el concepto de cónyuges. Italia no ha regulado los matrimonios entre personas del mismo sexo, por lo que no aplicará el Reglamento 1103/2016 a este matrimonio celebrado en Bélgica. En cambio, las autoridades belgas sí lo harían. Esto da lugar a una discontinuidad de las relaciones espaciales y a una evidente pérdida de salvaguarda jurídica dentro de la propia UE.

Una falta de definición, finalmente, también causa problemas en cuanto a la compatibilidad entre el Reglamento sobre los bienes matrimoniales y el Reglamento sobre las consecuencias patrimoniales de una unión registrada.

\section{3. Ámbito de aplicación temporal de los Reglamentos gemelos}

Los considerandos 69 del Reglamento 1103 y 67 del Reglamento 1104 establece que, para calcular los periodos y plazos, debe aplicarse el Reglamento 1182/71, del Consejo de 28 de mayo de 2001, por la que se crea una red Judicial Europea en materia civil y mercantil. Y de manera específica en el artículo 70 de los Reglamentos gemelos se diferencia dos fechas atendiendo al ámbito de aplicación temporal:

- La fecha de entrada en vigor a los 20 días, a contar desde su publicación el día 8 de julio de 2016, es decir, 28 de julio.

- La fecha de entrada en vigor de ambos Reglamento, que es el 29 de enero de $2019^{48}$. Fecha a partir de la que ambos tienen aplicación.

Esta diferencia entre la entrada en vigor de los instrumentos y la fecha de su aplicación permitió la publicación del contenido de los reglamentos, la adaptación de las normativas internas de los Estados miembros y, posiblemente, una mayor adhesión a la cooperación reforzada en asuntos como éste, en los que la integración y la unificación son complicadas ${ }^{49}$. En otras palabras, la primera fecha (la fecha de entrada en vigor) es

48 The exception is made for Articles 63 and 64, which deal with the information that Member States must provide to the Commission, on the one hand, and the drawing up of lists, certificates, forms and consultation procedures to do so, on the other (Articles 65, 66 and 67).

49 H. MотA, 'Regímenes matrimoniales y sucesión después de la disolución por muerte de un matrimonio transfronterizo: un caso de estudio’ (2019) 21 Revista Internacional de Legislación y Jurisprudencia 58. 
importante para los Estados miembros y sus instituciones responsables de la preparación de las disposiciones nacionales de aplicación. Tiene poca relevancia para los profesionales como jueces, abogados, notarios o mediadores; porque para ellos, la segunda fecha (la fecha de aplicación de los Reglamentos gemelos) es la más importante, ya que es el punto de inflexión a partir del cual las disposiciones nacionales fueron modificadas por las normas imperativas de la UE.

En general, los Reglamentos gemelos se aplican a partir del 29 de enero de 2019, sin embargo, las reglas más precisas de entrada en vigor de las normas establecidas en ambas normas se establecen en los artículos 69 (Disposiciones transitorias), donde se regula como norma general que, los reglamentos se aplican únicamente a los procedimientos judiciales iniciados, a los documentos públicos con fuerza ejecutiva formalizados o registrados y a las transacciones judiciales aprobadas o concluidas a partir del 29 de enero de 2019 (apartado 1 del artículo 69 de ambos Reglamentos).

Es importante destacar que las disposiciones transitorias del artículo 69 se refieren únicamente a la aplicación de los Reglamentos gemelos a los Estados miembros que participan en la cooperación reforzada en el momento en que los reglamentos entran en vigor, porque para los Estados miembros que se unan a la cooperación reforzada en una fecha posterior, se emitirá una decisión de la Comisión que establecerá disposiciones transitorias adaptadas teniendo en cuenta el acuerdo con dicho Estado. Se trata de una práctica habitual en el caso de los instrumentos de cooperación reforzada (véase, por ejemplo, la decisión de la Comisión sobre la adhesión de Estonia al Reglamento Roma III) y también podría compararse con las fechas específicas de entrada en vigor de los instrumentos de la UE para los Estados que acaban de adherirse a ella (por ejemplo, el Reglamento Bruselas II bis entró en vigor el 1 de marzo de 2005, pero para Croacia, que se adhirió a la UE el 1 de julio de 2013, es aplicable a partir de esa fecha).

También hay que tener en cuenta que el considerando 69 del Reglamento sobre los bienes matrimoniales y el considerando 67 del Reglamento sobre las consecuencias patrimoniales de las uniones registradas establecen que el Reglamento $n^{\circ} 1182 / 71$ del Consejo, de 3 de junio de 1971, por el que se determinan las normas aplicables a los plazos, fechas y términos, se aplica para el cálculo de los plazos y términos previstos en los Reglamentos gemelos.

Esta diferencia entre la entrada en vigor y la fecha de su aplicación, permite dar a conocer su contenido, la adaptación de normativas internas de los Estados y la posibilidad de mayor adhesión a la cooperación reforzada en materias como esta donde la integración y unificación son complicadas ${ }^{50}$.

50 H. MOTA, Regímenes matrimoniales y sucesión después de la disolución por muerte de un matrimonio transfronterizo: un caso de estudio, Revista Internacional de Legislación y Jurisprudencia, Vol. 21, diciembre 2019, p. 58. Aún desde un punto de vista temporal, el Reglamento 2016/1103 se aplicará a las acciones iniciadas a partir del 29.01.2019 y a los instrumentos auténticos formalizados y registrados a partir de esa fecha y a los acuerdos judiciales aprobados o concluidos al respecto. plazos de entrega; sin embargo, de conformidad con el art. 69, si la acción interpuesta en el Estado miembro de origen se presentó antes del 29.01.2019, las sentencias dictadas después de esa fecha se reconocerán y ejecutarán de conformidad con el Reglamento si se han respetado sus normas de jurisdicción; la ley aplicable según el Reglamento 2016/1103 afectará los matrimonios celebrados solo después del 29.01.2019, pero la elección de la ley hecha después de esa fecha se permitirá incluso si el matrimonio se celebró anteriormente ; en otros casos, y en lo que respecta a los tribunales portugueses, las reglas de conflicto del DIP portugués ( artículos 52, 53 y 54 del CC) con respecto a la ley aplicable y las reglas sobre 
En suma, el Reglamento 2016/1103 al igual que el Reglamento 2016/1104 determinan que se aplicará a partir del 29 de enero de 2019, día que entra en vigor, a las acciones judiciales que se ejerciten ante sus tribunales, a los documentos públicos que se formalicen y a las transacciones judiciales que se aprueben, respecto de los regímenes económicos matrimoniales (ex art. 69.1) siempre que se produzcan "repercusiones transfronterizas.

Es importante destacar que las disposiciones transitorias reguladas en el artículo 69, referidas a la aplicación vinculante de los Reglamentos gemelos en los Estados miembros que participan en la cooperación reforzada desde el momento que ambos entran en vigor. Para los Estados miembros que se unan a la cooperación reforzada en una fecha posterior, se emitirá una decisión de la Comisión que establecerá disposiciones transitorias adaptadas teniendo en cuenta el acuerdo con dicho Estado. Esta es una práctica habitual en el caso de los instrumentos de cooperación reforzada (véase, por ejemplo, la decisión de la Comisión sobre la adhesión de Estonia al Reglamento Roma III ${ }^{51}$ ) y también podría compararse con las fechas específicas de entrada en vigor de los instrumentos de la UE en relación con los Estados que acaban de adherirse a la UE (por ejemplo, el Reglamento Bruselas II bis entró en vigor el 1 de marzo de 2005, pero para Croacia, que se adhirió a la UE el 1 de julio de 2013, es aplicable a partir de esa fecha).

Además, hay que tener en cuenta que tanto el considerando 69 del Reglamento sobre los bienes matrimoniales, como el considerando 67 del Reglamento sobre los efectos patrimoniales de las uniones registradas, requieren de lo establecido en el Reglamento $\mathrm{n}^{\mathrm{o}}$ 1182/71 del Consejo, de 3 de junio de 1971, porque en el citado Reglamento se determinan las normas aplicables a los plazos, fechas y términos, se aplica para el cálculo de los plazos y términos previstos en los Reglamentos gemelos ${ }^{52}$.

\subsection{1. Ámbito temporal de aplicación de las disposiciones de competencia judicial}

La libertad de elección del órgano jurisdiccional y las normas de competencia deben tener en cuenta el alcance temporal que regula el Reglamento 2016/1103 y el Reglamento 2016/1104, en sus artículos 69 y 70. Por ello, solo serán aplicables a procedimientos iniciados después de su entrada en vigor, salvo que los miembros del matrimonio hayan realizado un acuerdo de elección cuya validez se somete a lo establecido en el Reglamento, o de las disposiciones publicadas que entraron en aplicación anteriormente.

Así pues, las normas jurisdiccionales en las relaciones transfronterizas están fuertemente relacionadas con el ámbito de aplicación temporal establecidas en los dos Reglamentos, que regulan como posibles escenarios temporales:

procedimiento civil ( artículos 62,63, 978 a 985 de la CPC) con respecto a la jurisdicción internacional y el reconocimiento de sentencias extranjeras.

51 Commission Decision (EU) 2016/1366 of 10 August 2016 confirming the participation of Estonia in enhanced cooperation in the area of the law applicable to divorce and legal separation [2016] C/2016/5137, OJ L 216.

52 OJ L 124, 8.6.1971. 


\begin{tabular}{|l|l|}
\hline \multicolumn{1}{|c|}{ Ámbito temporal } & \multicolumn{1}{c|}{ Aplicación de los Reglamentos gemelos } \\
\hline $\begin{array}{l}\text { Acciones interpuestas y resueltas } \\
\text { antes del } 29 \text { de enero de } 2019\end{array}$ & $\begin{array}{l}\text { La competencia judicial internacional quedará sometida } \\
\text { a la norma nacional de estado miembro sin aplicación } \\
\text { del Reglamento }\end{array}$ \\
\hline $\begin{array}{l}\text { Acciones interpuestas antes de la } \\
\text { entrada en vigor del Reglamento, } \\
\text { pero resueltas con fecha 29 de } \\
\text { enero de 2019 o posteriormente }\end{array}$ & $\begin{array}{l}\text { Admite la posibilidad de que sea reconocida y ejecutada } \\
\text { atendiendo a lo dispuesto capítulo IV del Reglamento. } \\
\text { Se amplia así la eficacia extraterritorial de las decisiones } \\
\text { emitidas por los órganos jurisdiccionales de un Estado, } \\
\text { porque sus efectos y aplicación serán en otro Estado. } \\
\text { Esto solo será posible cuando se trate de Estados que } \\
\text { participen de la cooperación reforzada, y sus foros de } \\
\text { competencia no resulten contradictorios }\end{array}$ \\
\hline
\end{tabular}

Podría plantearse la cuestión de cómo debe entenderse la expresión "procedimientos iniciados a partir de la entrada en vigor del Reglamento", especialmente en el caso de que se interponga un recurso con posterioridad. Como señala Biagoni, a falta de una aclaración en el artículo 69, debe tenerse en cuenta la incoación del procedimiento en primera instancia. Por otra parte, en el artículo 14 que define el momento de acudir a un tribunal (al enumerar los trámites procesales que deben tenerse en cuenta), el Reglamento de los gemelos aporta claridad al término "incoación del procedimiento" se adoptó teniendo en cuenta las normas De litispendencia y acciones conexas, también es pertinente para evaluar si se deben aplicar los Reglamentos gemelos, así como señalar que lo que importa es la fecha de incoación del procedimiento principal; la fecha de presentación de una demanda accesoria, una reconvención o una solicitud de medida cautelar o provisional es poco relevante para la aplicación de los Reglamentos gemelos.

Dado que ambos Reglamentos entraron en vigor hace relativamente poco tiempo, en la práctica siguen planteándose las cuestiones relativas al ámbito temporal de aplicación de las disposiciones jurisdiccionales. Em este sentido, el Tribunal del Condado de Zagreb, en su decisión de 8 de julio de 2020, tuvo que decidir si los tribunales croatas eran competentes para determinar los bienes matrimoniales de los nacionales croatas situados en Austria. El demandante indicaba en el recurso que el tribunal croata debía declararse competente basándose en las disposiciones del Reglamento sobre los bienes matrimoniales. Sin embargo, en segunda instancia se consideró correctamente que el caso no entra en el ámbito de aplicación temporal del Reglamento de régimen económico matrimonial, ya que el procedimiento se inició en 2017, es decir, que el procedimiento se inició antes del 29 de enero de 2019, considerando para la competencia las disposiciones nacionales de Derecho internacional privado como aplicables ${ }^{54}$.

Por el contrario, en una decisión de 16 de marzo de 2021, el Tribunal de Apelación de Arnhem-Leeuwarden (Gerechtshof Arnhem-Leeuwarden) señaló que, dado que la de-

53 G. BIAGONI, 'Article 69. Transitional Provisions' in I. VIARENGO and P. FRANZINA (eds.), The EU Regulations on the Property Regimes of International Couples, A Commentary, Edward Elgar, Cheltenham 2020, pp. 484 - 488.

54 County Court in Zagreb (Croatia), decision of 8 July 2020, No. G ž Ob 1137/2019-2. 
manda se presentó ante el tribunal después del 29 de enero de 2019, el Reglamento sobre bienes matrimoniales tenía aplicación atendiendo a su ámbito temporalmente (artículo 69 , apartado 1$)^{55}$.

\subsubsection{Alcance temporal de las disposiciones sobre reconocimiento y ejecución}

Cuando el procedimiento se haya incoado antes de la entrada en vigor del Reglamentos gemelos, estos instrumentos no serán aplicables para establecer la competencia o la ley aplicable. Sin embargo, si la decisión en tal caso se ha tomado ya después del 29 de enero de 2019, las disposiciones de los Reglamentos gemelos relativas al reconocimiento y la ejecución se aplicarán siempre que las normas de competencia que se aplicaron cumplan con las establecidas en el Capítulo II de los reglamentos.

Para que las normas nacionales de competencia se ajusten a las establecidas en el Capítulo II del Reglamento, parece ser suficiente que las normas nacionales atribuyan la competencia al mismo tribunal que las normas de los Reglamentos gemelos. En caso de que la competencia del tribunal se base en el acuerdo de elección del órgano jurisdiccional, es importante que tal acuerdo de elección de tribunal sea válido en virtud de lo dispuesto en el artículo 7 de cada uno de los Reglamentos sobre los gemelos ${ }^{56}$.

\begin{tabular}{|l|l|}
\hline \multicolumn{1}{|c|}{ Ámbito temporal } & \multicolumn{1}{|c|}{ Aplicación de los Reglamentos gemelos } \\
\hline $\begin{array}{l}\text { Procedimientos iniciados antes del 29 } \\
\text { de enero de 2019, pero resueltos a partir } \\
\text { de esa fecha }\end{array}$ & $\begin{array}{l}\text { Las resoluciones dictadas después del 29 de enero } \\
\text { de 2019 se están reconociendo y ejecutando de } \\
\text { acuerdo con el Capítulo IV de los Reglamentos } \\
\text { gemelos. Esto es posible siempre que las } \\
\text { normas de competencia aplicadas se ajusten } \\
\text { a las establecidas en el capítulo II de ambos } \\
\text { Reglamentos (artículo 69, apartado 2, de los } \\
\text { Reglamentos gemelos). Naturalmente, esto sólo } \\
\text { es posible para los Estados que participan en la } \\
\text { cooperación reforzada. }\end{array}$ \\
\hline $\begin{array}{l}\text { Procedimientos iniciados el 29 de enero } \\
\text { de 2019 o posteriormente }\end{array}$ & $\begin{array}{l}\text { Sin excepciones, las resoluciones dictadas después } \\
\text { del 29 de enero de 2019 se reconocen y ejecutan } \\
\text { de conformidad con los Reglamentos gemelos. }\end{array}$ \\
\hline
\end{tabular}

Aunque a largo plazo estas disposiciones transitorias se aplicarán menos que a la entrada en vigor del Reglamento de los gemelos, seguirán siendo relevantes.

\subsubsection{Aplicación temporal de las disposiciones sobre la ley aplicable}

De acuerdo con el apartado 3 del artículo 69, el capítulo III (Ley aplicable) se aplica únicamente a los cónyuges o parejas de hecho que contraigan matrimonio, o registren su

55 Court of Appeal of Arnhem-Leeuwarden (Gerechtshof Arnhem-Leeuwarden), decision of 16 March 2021, No. 200.277.891/01 (ECLI: NL: GHARL: 2021: 2490).

56 Vid. G. Biagoni, ‘Article 69. Transitional Provisions', op.cit. n. 11, p. 484-88. 
acuerdo de unión, o que especifiquen la ley aplicable a su régimen patrimonial después del 29 de enero de 2019 (día de entrada en vigor de ambos Reglamentos). Dicha limitación da lugar a cuatro escenarios diferentes ${ }^{57}$ :

\begin{tabular}{|l|l|}
\hline \multicolumn{1}{|c|}{ Marco temporal } & \multicolumn{1}{|c|}{ Aplicación de los Reglamentos Gemelos } \\
\hline $\begin{array}{l}\text { Un matrimonio o una unión registrada } \\
\text { celebrada antes del } 29 \text { de enero de 2019 } \\
\text { sin un acuerdo sobre la elección de la ley } \\
\text { aplicable o con un acuerdo celebrado antes } \\
\text { de esa fecha. }\end{array}$ & $\begin{array}{l}\text { En este caso, se aplican las normas } \\
\text { nacionales de Derecho internacional privado. }\end{array}$ \\
\hline $\begin{array}{l}\text { Un matrimonio o una unión registrada } \\
\text { celebrados antes del } 29 \text { de enero de 2019 } \\
\text { en los que se celebre un acuerdo sobre la } \\
\text { elección de la ley aplicable en esa fecha o } \\
\text { después de ella }\end{array}$ & $\begin{array}{l}\text { En tal caso, los tribunales considerarán el } \\
\text { acuerdo de elección de la ley en virtud del } \\
\text { Reglamento sobre los gemelos en la medida } \\
\text { en que el acuerdo sea válido (la validez se } \\
\text { establecerá con arreglo a las disposiciones } \\
\text { del reglamento). }\end{array}$ \\
\hline $\begin{array}{l}\text { Un matrimonio o una unión registrada } \\
\text { celebrados a partir del 29 de enero de 2019, } \\
\text { pero cuyo acuerdo sobre la elección de la } \\
\text { ley aplicable se haya celebrado antes de esa } \\
\text { fecha }\end{array}$ & $\begin{array}{l}\text { En este caso, los tribunales deben aplicar el } \\
\text { correspondiente Reglamento (1103 o 1104, } \\
\text { según proceda) y considerar si el acuerdo } \\
\text { de elección de la ley cumple los requisitos } \\
\text { establecidos en la legislación de la UE. }\end{array}$ \\
\hline $\begin{array}{l}\text { Un matrimonio o una unión registrada } \\
\text { celebrados a partir del 29 de enero de 2019 } \\
\text { sin acuerdo de elección de ley o con acuerdo } \\
\text { de elección de ley celebrado después de esta } \\
\text { fecha }\end{array}$ & $\begin{array}{l}\text { En este caso, los tribunales deben aplicar el } \\
\text { correspondiente Reglamento (1103 o 1104, } \\
\text { según proceda) y considerar si el acuerdo } \\
\text { de elección de la ley cumple los requisitos } \\
\text { establecidos en la legislación de la UE. }\end{array}$ \\
\hline
\end{tabular}

Es evidente que las normas sobre la ley aplicable de ambos Reglamentos no están vinculadas a la fecha de incoación del procedimiento (como sucede con normas jurisdiccionales), sino a la fecha de establecimiento de la relación jurídica ${ }^{58}$. La idea de esta elección está vinculada a la necesidad de seguridad jurídica y previsibilidad: la pareja debe saber de antemano qué ley se aplica a su régimen patrimonial. Si la pareja formaliza su relación después de la entrada en vigor de los Reglamentos gemelos, se ajusta a sus expectativas jurídicas de que este instrumento regulará la ley aplicable a su régimen patrimonial. Si, por el contrario, se casaron o registraron su sociedad de gananciales con anterioridad, los Reglamentos no serán aplicables a su situación y, en su lugar, se aplica-

57 On temporal scope of application for registered partnerships see also: F. DougAn and J. KRAMBERGER Škerl, 'Model clauses for registered partnerships under Regulation (EU) 2016/1104', in M. J. CAzORLA GONZÁLEZ and L. RUGGERI (eds), Guidelines for practitioners in cross-border family property and succession law (a collection of model acts accompanied by comments and guidelines for their drafting), Dykinson, Madrid 2020, p. 38.

58 Similar principle applies in other instruments on applicable law, for instance the Succession Regulation. 
rán las normas nacionales de conflicto de leyes (lo que la pareja esperaba razonablemente en el momento de formalizar su relación).

El apartado 3 del artículo 69 también establece que el capítulo III de los Reglamentos Gemelos se aplica a las parejas que "especifican la ley aplicable al régimen matrimonial o de pareja de hecho después del 29 de enero de 2019". Es decir, el Reglamento se aplica también a las parejas que formalizaron su relación con anterioridad, pero los acuerdos de elección de ley se celebraron en el periodo de tiempo en el que ambos Reglamentos ya era aplicables. Además, en la doctrina se argumenta que el término "especificar” también implica que los Reglamentos 2016/1103 y 2016/1104 también se aplica a las situaciones en las que el acuerdo de elección de ley se modifica o complementa después de esta fecha ${ }^{59}$. Naturalmente, esta regulación se ajusta a las expectativas legítimas de los cónyuges y copartícipes y esta disposición era necesaria para la coherencia de los instrumentos.

\section{4. Ámbito de aplicación territorial de los Reglamentos gemelos}

Los Reglamentos gemelos son vinculantes y directamente aplicable solo en los Estados miembros que participan en la cooperación reforzada, en virtud de la Decisión (UE) 2016/954: Alemania, Austria, Bélgica, Bulgaria, Chipre, Croacia, Eslovenia, España, Finlandia, Francia, Grecia, Italia, Luxemburgo, Malta, Países Bajos, Portugal, República Checa y Suecia. Este es el principio que se desprende del apartado 4 del artículo 20 del Tratado de la Unión Europea, que establece que los actos adoptados en el marco de la cooperación reforzada sólo vincularán a los Estados miembros participantes ${ }^{60}$.

Los demás Estados miembros de la UE se consideran terceros Estados a efectos de la aplicación del Reglamento. Cuando se plantea un caso sobre el régimen económico matrimonial ante los tribunales de los Estados miembros de la UE que no participan en la cooperación reforzada, éstos aplican su legislación nacional para establecer la competencia, la ley aplicable o las normas de reconocimiento y ejecución.

Un caso reciente ante el tribunal regional de Klaipėda (Lituania, un país que no participa en la cooperación reforzada), se refería a cónyuges que eran ciudadanos lituanos. Fueron residentes en Alemania durante muchos años y luego volvieron a Lituania con su hijo, donde iniciaron un proceso de divorcio. El tribunal estableció su jurisdicción para el divorcio, las responsabilidades parentales y la manutención de acuerdo con los reglamentos pertinentes de la UE. En cuanto a los bienes matrimoniales, dictaminó que, al no existir ningún reglamento de la UE que pudiera aplicarse a las relaciones patrimoniales de la pareja (Lituania no es parte del Reglamento sobre los bienes matrimoniales), el tribunal debía proceder aplicando la legislación nacional ${ }^{61}$.

Cabe señalar que, aunque el considerando 11 de los Reglamentos gemelos determina que la jurisdicción territorial es plenamente aplicable sólo en 18 países que participan en la cooperación reforzada, la ley de cualquier otro Estado miembro de la UE o

59 G. Biagoni, ‘Article 69. Transitional Provisions', op. cit. n. 11, p. 484-88.

60 In addition, acts adopted in the framework of enhanced cooperation are not regarded as part of the acquis, which has to be accepted by candidate States for accession to the EU.

61 Klaipeda regional court (Lithuania), decision of 20 May 2021, No. e2A-728-896/2021. 
incluso de un tercer país puede aplicarse en el marco de los Reglamentos gemelos debido al principio de aplicación universal (artículos 20 de los Reglamentos gemelos). Los artículos 62 de ambos reglamentos subrayan que ninguno de ellos afectará a la aplicación de los convenios bilaterales o multilaterales vigentes, excepto aquellos entre los Estados miembros, que prevalezcan sobre ellos. Moreno ${ }^{62}$ argumenta que, en lo que respecta a la ley aplicable, ésta se refiere principalmente al Convenio de La Haya de $1978^{63}$, que sigue aplicándose en Francia, los Países Bajos y Luxemburgo, así como a los convenios pertinentes firmados por los países escandinavos.

Por último, el ámbito de aplicación territorial es posible atendiendo a la elección de la ley aplicable o atendiendo a factores de conexión como la residencia habitual o la nacionalidad.

En un primer ámbito y a la vista de lo anterior, parece que las partes pueden elegir la ley aplicable de cualquier Estado miembro en aplicación del artículo 20, y en base al principio de libre elección regulado en el artículo 22 de cada Reglamento, incluyendo la ley de un Estado miembro no participante; sin embargo, en tal caso, habrá que tener en cuenta las limitaciones que el propio artículo establece referidas a la ley del Estado participante (o no) en la cooperación reforzada, y referenciadas en el primer apartado de este capítulo (Sección 1.3.1).

En consecuencia, la libre elección de la ley aplicable se reduciría a un máximo de seis sistemas jurídicos nacionales diferentes si las partes tienen doble nacionalidad; y a cuatro, si sólo tienen una cada una ${ }^{64}$. Las nacionalidades de los Estados miembros distintas de la jurisprudencia del TJUE deben estar en igualdad de condiciones ${ }^{65}$, sin que un Estado miembro pueda dar preferencia a su nacionalidad en función de sus normas nacionales.

Una opción para cada nacionalidad y lugar de residencia habitual diferente. Estas opciones pueden reducirse para los matrimonios del mismo sexo en doce Estados miembros de la UE que no contemplan su regulación: Croacia, República Checa, Chipre, Eslovenia, Grecia, Hungría, Italia, Letonia, Lituania, Polonia, Eslovaquia, Bulgaria y Rumanía; igualmente para las uniones registradas, que no están reguladas en los seis últimos Estados miembros mencionados.

Sobre la base de las posibles opciones y de algunos estudios realizados en el marco del proyecto PSEFS ${ }^{66}$, hay que abordar tres posibles escenarios que podrían afectar a los matrimonios o a las uniones registradas a la hora de determinar la ley aplicable. Difieren en cuanto a si se trata de un Estado miembro que participa en una cooperación reforzada o no. Las posibilidades son que ambas partes sean nacionales de los Estados miembros de la

62 G. Palao Moreno, 'Forum necessitatis', in I. Buigues and G. Palao Moreno (eds), Régimen económico matrimonial y efectos patrimoniales de las uniones registradas en la Unión Europea, Tirant lo Blanch, Valencia 2019, pp. 131-34.

63 A. Rodriguez Benot, 'Los efectos patrimoniales de los matrimonios y de las uniones registradas en la unión europea' (2019) 1 Cuadernos de Derecho Transnacional 9.

64 S. DE VIDO, 'The relevance of dual nationality in conflict-of-law issues relating to divorce and legal separation in Europe' Cuadernos de Derecho Transnacional, March 2012, 4, No 1, pp. 222-232.

65 Judgement of 7 July 1992. Case C-369/90. https://curia.europa.eu/juris/showPdf.jsf?docid=97581\&doclang=ES

66 Justice Project 'Personalized Solution in European Family and Succession Law (PSEFS)' No. 800821-JUST-AG- 2017/JUST-JCOO-AG-2017 https://www.euro-family.eu Vid. Atlas: https://www. euro-family.eu/atlas. 
UE que participan en la cooperación reforzada (véase el considerando 11 del Reglamento sobre los gemelos), que sólo uno de los cónyuges o parejas sea nacional de dicho Estado y el otro no; y cuando ninguno de los dos sea nacional de dicho Estado. En este último caso, el Reglamento Roma III y las normas nacionales pertinentes se aplicarán a los matrimonios, y sólo estas últimas en lo que respecta a las uniones registradas.

El ámbito territorial de aplicación, aunque simple en apariencia, contiene asimetrías que deberán ser aclaradas de acuerdo con lo dispuesto en el artículo 26 (1) de cualquiera de los reglamentos en cada caso concreto ${ }^{67}$. Los factores de conexión pertinentes son $^{68}$ : el lugar de residencia, la nacionalidad o la conexión más estrecha de los cónyuges; y la ley del Estado en el que se creó la unión para las parejas de hecho. En el caso de estas últimas, se evita la conexión con la nacionalidad o la residencia habitual, ya que esto podría implicar la aplicación de una ley que no reconozca la institución de la pareja registrada, aunque la ley aplicable sea de carácter universal.

En consecuencia, las partes pueden haber constituido su unión en un Estado y en ese momento o posteriormente tener su residencia habitual en otro Estado. Independientemente de que los cónyuges o parejas sean del mismo o distinto sexo, todos los ciudadanos europeos y los miembros de su familia tienen derecho a la movilidad transfronteriza dentro del territorio comunitario. para ellos y los miembros de su familia. Esta situación puede ser complicada en términos de validez formal, ya que la unión debe ser registrada, y por lo tanto se requiere un acto formal ante una autoridad pública, y en muchos sistemas legales no se requiere un período previo de convivencia.

Por otro lado, el ámbito territorial basado en los factores de conexión como la residencia habitual o la nacionalidad

Hay que tener en cuenta que las circunstancias de la residencia o la residencia habitual son variables y, por tanto, pueden provocar cierta distorsión, bien porque existen circunstancias indeterminadas como la definición de ambos términos, bien porque el momento de determinar la residencia variará en función del país.

En el asunto C-523/0769, el TJUE dictaminó que la residencia habitual corresponde al lugar donde la persona tiene cierta integración en un entorno social y familiar. Por lo tanto, el órgano judicial nacional debe determinar el Estado de la residencia habitual en el caso concreto basándose en las circunstancias específicas.

Existen diferencias en la legislación de los distintos Estados miembros de la UE a la hora de determinar la residencia habitual:

- Cuando abordamos la indeterminación del término residencia/domicilio, encontramos diferentes soluciones. Mientras que en Portugal ${ }^{70}$ y Polonia ${ }^{71}$ el domicilio es el lugar de la residencia habitual, en Irlanda existe un domicilio de origen equivalente al concepto de residencia habitual y un domicilio de elec-

67 M. SOTO MOYA: 'Ámbito de aplicación personal del Reglamento 2016/1104 sobre régimen patrimonial de la pareja registrada' (Diciembre 2020) 23 Revista internacional de doctrina y jurisprudencia pp.7-8.

68 S. DE VIDO, 'The relevance of dual nationality in conflict-of-law issues relating to divorce and legal separation in Europe' Cuadernos de Derecho Transnacional, March 2012, 4, № 1, pp. 222-232.

69 Case C-523/07, A., ECLI:EU:C:2020:531

70 https://ec.europa.eu/immigration/country-specific-information/portugal/family-member_en

71 https://ec.europa.eu/immigration/country-specific-information/poland/family-member_en 
ción, que se identifica con el lugar donde existe una intención permanente o indefinida de residir ${ }^{72}$. En Italia ${ }^{73}$, el domicilio es el lugar donde se encuentra la actividad profesional y los intereses de la persona, que no tiene por qué coincidir con la residencia (donde vive habitualmente).

- Además, los requisitos relativos a la duración de la residencia varían en función del país, y van desde los 40 días de residencia previa a la presentación de la solicitud en Escocia hasta los tres meses de residencia previa exigidos en Chipre, o los 12 meses requeridos en Bélgica o Malta. Sin embargo, la última residencia o domicilio también es indeterminada, como en Grecia, Inglaterra o Gales, donde basta con tener un domicilio en el territorio.

Sin embargo, todos los países europeos tienen algo en común. Todos ellos consideran que la residencia o el domicilio y la nacionalidad son elementos de conexión estrechos a la hora de regular las normas de Derecho internacional privado. Así, estos factores se utilizan para determinar el órgano internacional competente que debe resolver los con-flictos derivados de las consecuencias patrimoniales de los matrimonios o de las uniones registradas, en los litigios con miembros de distinta nacionalidad y en la división de los bienes por anulación, separación, divorcio/disolución o fallecimiento.

Por último, hay que destacar que existen elementos de conexión con el reglamento de sucesiones: el artículo 4 de los Reglamentos gemelos, cuando la sucesión de un miembro de una pareja registrada o de un cónyuge se plantea ante un tribunal de un Estado miembro en virtud del Reglamento (UE) $n^{\circ}$ 650/2012, pero esta cuestión se trata en otro capítulo.

\section{OBSERVACIONES FINALES}

La armonización del derecho de familia en Europa avanza con la adopción de los Reglamentos gemelos, que suponen un paso adelante para las familias transfronterizas, ya que su finalidad es evitar decisiones irreconciliables en los distintos Estados miembros, en aras del funcionamiento armónico de la justicia, Ambos Reglamentos suponen un avance en el derecho privado europeo, en el marco de la cooperación reforzada y con la flexibilidad de una aplicación universal de su artículo 20.

En este sentido los nuevos instrumentos internacionales, procesales y civiles privados contribuyen a dar solución a las cuestiones derivadas de la movilidad de personas de distintas nacionalidades dentro de Europa, desde el ámbito material, temporal y personal, siguiendo las disposiciones para la determinación del tribunal competente y la ley aplicable al caso concreto, en el que se debe atender a los Estados con más de un ordenamiento jurídico. Así pues, se han introducido normas de conflicto de leyes armonizadas para evitar resultados contradictorios, ya que la norma principal debe garantizar que el régimen económico matrimonial o los bienes de la sociedad de gananciales se rijan por una ley previsible con la que guarden una estrecha relación. Dichos instrumentos deter-

72 P. ROGERSON, "Habitual Residence: The New Domicile?", The International and Comparative Law Quarterly, Vol. 49, No. 1, January, 2000, p.90. The author considers that is necessary settle intention of the person.

73 https://ec.europa.eu/social/main.jsp?catId=1116\&langId=en\&intPageId=4629 
minan el ámbito territorial, temporal, personal y material respetando el principio de libre circulación como derecho regulado en la UE a la hora de establecer la residencia de los miembros de la pareja registrada o de los cónyuges, independientemente de que sean parejas del mismo o distinto sexo.

En conclusión, el Reglamento de Gemelos constituye un paso más hacia la unificación del Derecho de familia internacional privado, dirigido a la creación de un marco uniforme de normas de conflicto para resolver las cuestiones transfronterizas que surjan en el seno de la familia y no a la unificación de sus normas sustantivas. El Twin Regulations se aplica únicamente a las situaciones transfronterizas y no a los casos puramente nacionales. Para determinar si el Reglamento gemelo se aplica en un caso concreto, hay que estudiar y tener en cuenta su alcance temporal, territorial y material. Todo ello viene determinado por el respeto al principio de libre circulación como derecho regulado en la UE. Por último, hay que recordar que ambos reglamentos entraron plenamente en vigor el 29 de enero de 2019, y a partir de ese momento no se aplica el derecho internacional privado de los Estados miembros, participantes en la cooperación reforzada. 